\title{
A quantitative analysis of the impact of wind turbines on operational Doppler weather radar data
}

\section{Norin}

Atmospheric Remote Sensing Unit, Research Department, Swedish Meteorological and Hydrological Institute, Norrköping, Sweden

Correspondence to: L. Norin (lars.norin@smhi.se)

Received: 26 July 2014 - Published in Atmos. Meas. Tech. Discuss.: 27 August 2014

Revised: 9 January 2015 - Accepted: 10 January 2015 - Published: 5 February 2015

\begin{abstract}
In many countries wind turbines are rapidly growing in numbers as the demand for energy from renewable sources increases. The continued deployment of wind turbines can, however, be problematic for many radar systems, which are easily disturbed by turbines located in the radar line of sight. Wind turbines situated in the vicinity of Doppler weather radars can lead to erroneous precipitation estimates as well as to inaccurate wind and turbulence measurements. This paper presents a quantitative analysis of the impact of a wind farm, located in southeastern Sweden, on measurements from a nearby Doppler weather radar. The analysis is based on 6 years of operational radar data. In order to evaluate the impact of the wind farm, average values of all three spectral moments (the radar reflectivity factor, absolute radial velocity, and spectrum width) of the nearby Doppler weather radar were calculated, using data before and after the construction of the wind farm. It is shown that all spectral moments, from a large area at and downrange from the wind farm, were impacted by the wind turbines. It was also found that data from radar cells far above the wind farm (near $3 \mathrm{~km}$ altitude) were affected by the wind farm. It is shown that this in part can be explained by detection by the radar sidelobes and by scattering off increased levels of dust and turbulence. In a detailed analysis, using data from a single radar cell, frequency distributions of all spectral moments were used to study the competition between the weather signal and wind turbine clutter. It is shown that, when weather echoes give rise to higher reflectivity values than those of the wind farm, the negative impact of the wind turbines is greatly reduced for all spectral moments.
\end{abstract}

\section{Introduction}

As a response to the increasing demand for renewable energy the number of wind turbines is growing rapidly in many countries around the world. The worldwide installed cumulative energy capacity of wind turbines has shown a more-than13-fold increase during 2001-2013. In Sweden, the wind power capacity has increased even more, 15 times, during the same period (Global Wind Energy Council, 2014). In the coming years many more wind turbines are expected to be built and existing, older ones are likely to be replaced by larger, next-generation turbines. Modern wind turbines are large structures, many reaching $150 \mathrm{~m}$ above the ground. Clusters of densely spaced wind turbines, so-called wind farms, are being built both on- and offshore.

The continued deployment of wind turbines and wind farms presents a problem for many radar systems, which are easily disturbed by wind turbines located in the radar line of sight. Due to their rotating blades, interference caused by wind turbines is more severe for radar systems than interference caused by stationary structures (e.g. masts or towers). Many Doppler radars use a clutter filter that suppresses echoes originating from objects with no or little radial velocity, but such filters do not work for moving objects such as the rotating blades of a wind turbine. It has been shown that wind turbines located in the line of sight of Doppler radars can have a detrimental impact on the performance of both military and civilian radar systems (see, e.g., Poupart, 2003; Department of Defense, 2006; Lemmon et al., 2008; Lute and Wieserman, 2011).

Doppler weather radars, employed by meteorological and hydrological services, can also be negatively affected by nearby wind turbines. Weather radars are valuable tools for 
monitoring precipitation and wind shear as well as for observing hazardous events such as hailstorms, heavy rainfall, and tornadoes. Information from weather radars is also used as input to numerical weather prediction and floodforecasting models. Errors in weather radar data may propagate to affect the output of such forecast systems (Rossa et al., 2011).

Several studies dedicated to wind turbine impact on weather radar data have presented images of radar composites that convincingly show that wind farms indeed can be detected by weather radars (see, e.g., Burgess et al., 2008; Crum and Ciardi, 2010; Vogt et al., 2011). In other studies, time series of raw radar data have been recorded in order to perform detailed analyses of the impact of wind turbines by spectral analysis. Gallardo et al. (2008) collected raw radar data over a few months from a Spanish C-band weather radar to analyse the impact of a large wind farm, while Isom et al. (2009) used several hours' worth of raw data from two US S-band weather radars to investigate the same phenomenon. Toth et al. (2011) used a mobile X-band Doppler radar to study the impact of wind turbines from close range. However, only a few analyses of wind turbine impact on long time series of operational weather radar data have been published (Haase et al., 2010; Norin and Haase, 2012).

The main objective of this study is to analyse the impact of wind turbines on operational Doppler weather radar volume data. This study thus extends the work by Haase et al. (2010) and Norin and Haase (2012). In this study the wind turbine impact on all three spectral moments (the radar reflectivity factor, radial velocity, and spectrum width) have been investigated in order to improve the understanding of wind turbine impact on Doppler weather radar data. In total, 6 years' worth of operational polar volume data were used for the data analysis.

The structure of the paper is as follows. The technical characteristics of the Swedish radars are described in Sect. 2. The radar data set together with the analysed wind farm are presented in Sect. 3. In Sect. 4.1 the impact of wind turbines on data from a single radar scan is shown by comparing average values of the spectral moments, before and after the construction of the wind farm. In Sect. 4.2 the wind turbine impact on polar volume data is investigated. Section 4.3 presents a detailed analysis of the wind turbine impact on data from a single radar cell, by examining frequency distributions for all spectral moments as a function of reflectivity from a reference radar cell. The competition between the weather signal and wind turbine clutter is investigated in Sect. 4.4, and in Sect. 5 the impact of the wind farm on measurements far above the radar is discussed. Finally, in Sect. 6, a summary of the study is given and conclusions of the analyses are drawn.

\section{The Swedish weather radars}

The Swedish weather radar network consists of 12 horizontally polarised Ericsson C-band Doppler radars, providing almost complete national coverage. The radars perform azimuthal scans of $360^{\circ}$ around a vertical axis for 10 tilt angles, $\theta$, ranging from $\theta=0.5^{\circ}$ to $\theta=40^{\circ}$. The antenna rotational speed is $v_{r}=2 \mathrm{rpm}$. Together, these scans make up polar volume data sets which are provided with an update time of $15 \mathrm{~min}$.

The data processing is managed by the radar signal processor. The four lowest scans $\left(\theta=0.5^{\circ}\right.$ to $\left.\theta=2.0^{\circ}\right)$ use a different measurement strategy than the highest six scans $\left(\theta=2.5^{\circ}\right.$ to $\left.\theta=40.0^{\circ}\right)$. The received signal is digitised using an 8 bit analogue-to-digital converter with a sampling rate of 0.9 (1.8) MHz for the lower (higher) scans, corresponding to $167(83) \mathrm{m}$ range bins. A radar cell consists of 12 range bins, and thus the range resolution for a radar cell is $2(1) \mathrm{km}$ for the lower (higher) scans. The lower scans also use a lower set of pulse repetition frequencies (PRFs), $450 \mathrm{~Hz}$ or $600 \mathrm{~Hz}$, whereas the higher tilt angles use a higher set of PRFs (900 or $1200 \mathrm{~Hz}$ ).

For all scans the signal processor uses 32 measurements from each PRF to compute a Fourier transform, which means that the azimuthal resolution depends on the set of PRFs. For the lower scans the azimuthal resolution is $360 /\left\{60 /\left[v_{r}\left(32 / \mathrm{PRF}_{1}+32 / \mathrm{PRF}_{2}\right)\right]\right\} \approx 1.49^{\circ}$, whereas for the higher scans the azimuthal resolution is approximately $0.75^{\circ}$. Data are, however, output in matrices consisting of $120 \times 420$ radar cells for every scan. The apparent azimuthal resolution is thus $360 / 420 \approx 0.86^{\circ}$ for all scans.

The main radar lobe has a half-power beam width of $0.9^{\circ}$. The first sidelobes appear at approximately $2.5^{\circ}$ near $-30 \mathrm{~dB}$ in the horizontal direction and at approximately $2^{\circ}$ near $-30 \mathrm{~dB}$ in the vertical direction (a vertical cut of the antenna pattern is shown in Sect. 5).

Doppler weather radars measure three spectral moments (see, e.g., Doviak and Zrnić, 2006): the radar reflectivity factor (hereafter referred to as reflectivity), radial velocity, and spectrum width. These spectral moments are used to estimate quantities such as precipitation rate, wind speed, and turbulence.

Reflectivity, $Z$, is the power of the returned signal and is measured by the radar in units of dBZ. The minimum detectable signal of the Swedish radars is better than $-114 \mathrm{dBm}$. Whenever the radar receives a signal stronger than the minimum detectable signal, a hit is recorded and converted to reflectivity. The Swedish weather radars have a dynamic range of $>85 \mathrm{~dB}$ and measure $Z$ between -30 and $71.6 \mathrm{dBZ}$ in steps of $0.4 \mathrm{dBZ}$. The minimum value $(-30 \mathrm{dBZ})$ represents all measurements ranging from $-\infty$ to $-30 \mathrm{dBZ}$. Such values are classified as undetected measurements.

Radial velocity, $V$, is obtained as the first moment of the power-normalised Doppler spectrum. Two PRFs are used al- 
Table 1. Selected characteristics of Swedish weather radars.

\begin{tabular}{lll}
\hline & $0.5^{\circ}, 1.0^{\circ}$, & $2.5^{\circ}, 4.0^{\circ}, 8.0^{\circ}$, \\
Tilt angles & $1.5^{\circ}, 2.0^{\circ}$ & $14.0^{\circ}, 24.0^{\circ}, 40.0^{\circ}$ \\
\hline Transmit power & $250 \mathrm{~kW}$ & $250 \mathrm{~kW}$ \\
Wavelength & $5.35 \mathrm{~cm}$ & $5.35 \mathrm{~cm}$ \\
Gain & $44.7 \mathrm{~dB}$ & $44.7 \mathrm{~dB}$ \\
Pulse width & $0.5 \mu \mathrm{s}$ & $0.5 \mu \mathrm{s}$ \\
Beam width & $0.9^{\circ}$ & $0.9^{\circ}$ \\
PRFs & $600 / 450 \mathrm{~Hz}$ & $1200 / 900 \mathrm{~Hz}$ \\
Rotational speed & $2 \mathrm{rpm}$ & $2 \mathrm{rpm}$ \\
Measurement radius & $240 \mathrm{~km}$ & $120 \mathrm{~km}$ \\
Radial resolution & $2 \mathrm{~km}$ & $1 \mathrm{~km}$ \\
Azimuthal resolution & $0.86^{\circ}$ & $0.86^{\circ}$ \\
Range cells & 120 & 120 \\
Azimuth gates & 420 & 420 \\
Max unambiguous velocity & $24 \mathrm{~m} \mathrm{~s}^{-1}$ & $48 \mathrm{~m} \mathrm{~s}$ \\
\hline
\end{tabular}

ternatively to allow real-time dealiasing of the radial velocities. The maximum unambiguous velocity is $\pm 24 \mathrm{~m} \mathrm{~s}^{-1}$ for the four lowest scans and $\pm 48 \mathrm{~m} \mathrm{~s}^{-1}$ for the six highest scans. The radial velocity resolution is $0.1875 \mathrm{~m} \mathrm{~s}^{-1}\left(0.375 \mathrm{~m} \mathrm{~s}^{-1}\right.$ for the higher scans). Undetected reflectivity measurements $(Z \leq-30 \mathrm{dBZ})$ result in unreliable estimates of radial velocity, and such measurements are therefore classified as undetected.

Spectrum width, $W$, is calculated as the square root of the second moment about the first of the power-normalised spectrum. The measurements of the spectrum width fall into one of four classes: $0-1,1-2,2-3$, and $>3 \mathrm{~m} \mathrm{~s}^{-1}$ for the four lowest scans and $0-2,2-4,4-6$, and $>6 \mathrm{~m} \mathrm{~s}^{-1}$ for the six highest scans. As for radial velocity, undetected reflectivity measurements $(Z \leq-30 \mathrm{dBZ})$ result in unreliable estimates of spectrum width, and such measurements are therefore classified as undetected.

Invalid measurements are produced when the radar does not perform correctly, such as when failing to find a requested angle in azimuth or elevation or if the transmitter is not ready in time. Invalid measurements for any spectral moment are given separate values by the radar.

All radars in the network are equipped with clutter filters which are used to suppress ground echoes. The clutter filter is turned on for all scans. Ground echo suppression is obtained by omitting amplitudes from the three frequency channels closest to 0 in the frequency spectrum (channel 0, 1, and 31). For the lowest four scans (using the lower set of PRFs) this removes echoes with radial velocities less than $\pm 1 \mathrm{~m} \mathrm{~s}^{-1}$; for the highest six scans radial velocities with $\pm 1.5 \mathrm{~m} \mathrm{~s}^{-1}$ are omitted. To protect the radar receiver from overload the signal is damped by $60 \mathrm{~dB}$ near the radar, making the data of the first two rows of radar cells unusable.

Relevant radar characteristics are summarised in Table 1.

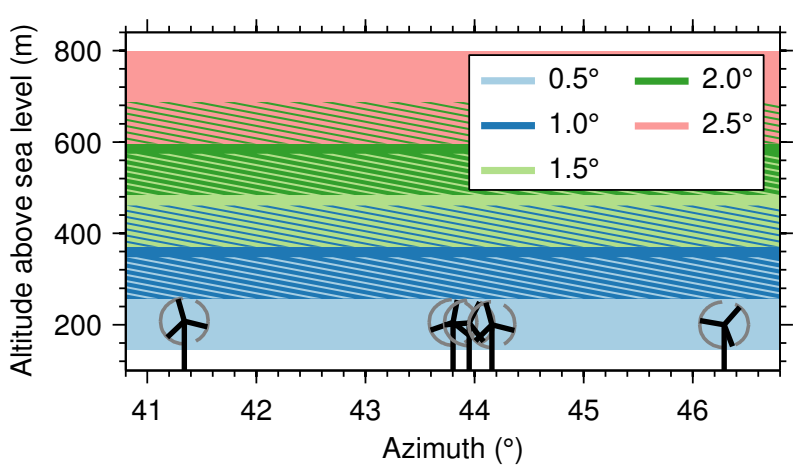

Figure 1. Schematic plot of the Brunsmo wind farm. The positions and heights of the wind turbines are shown together with the altitudes of the half-power beam width of the main radar lobe for the five lowest tilt angles $\left(0.5^{\circ} \leq \theta \leq 2.5^{\circ}\right)$ at the wind farm.

\section{Data set and wind turbines}

Operational polar volume data from the Swedish weather radars are available from the year 2005 and later. Some changes were made in the radar scan strategy as well as to the radar hardware during 2007, but from 2008 the radar scan strategy and measurement techniques have remained unaltered. Radar data from 2008 and later hence constitute a homogeneous data set.

In order to investigate the impact of wind turbines on Doppler weather radar data, we have analysed operational polar volume data from weather radar Karlskrona $\left(56.2955^{\circ} \mathrm{N}, 15.6103^{\circ} \mathrm{E}\right)$ for a period of 6 years (1 January 2008 to 31 December 2013). Throughout this period no significant data gaps exist, and radar service records do not show any indication of radar malfunctioning occurring during this period.

Brunsmo wind farm is located in southeastern Sweden, approximately $13 \mathrm{~km}$ northeast of weather radar Karlskrona. This wind farm consists of five General Electric 2.5 MW wind turbines with total heights of $150 \mathrm{~m}$ above the ground. These wind turbines have a rotor diameter of $100 \mathrm{~m}$, a cutin wind speed of $3.5 \mathrm{~m} \mathrm{~s}^{-1}$, and a cut-out wind speed of $25 \mathrm{~m} \mathrm{~s}^{-1}$.

The wind turbines were erected in October and November 2009, and the wind farm became operational in April 2010. The proximity of the Brunsmo wind farm to weather radar Karlskrona together with the date of the wind farm's start of operations (near the middle of the homogeneous radar data set) makes the Brunsmo wind farm well suited for a detailed study.

Figure 1 shows a schematic picture of the locations and heights of the wind turbines of the Brunsmo wind farm together with the altitudes of the radar lobes' half-power beam width for the five lowest tilt angles $(0.5,1.0,1.5,2.0$, and $2.5^{\circ}$ ) at the wind farm, assuming standard propagation conditions. From Fig. 1 it is seen that all wind turbines are in 

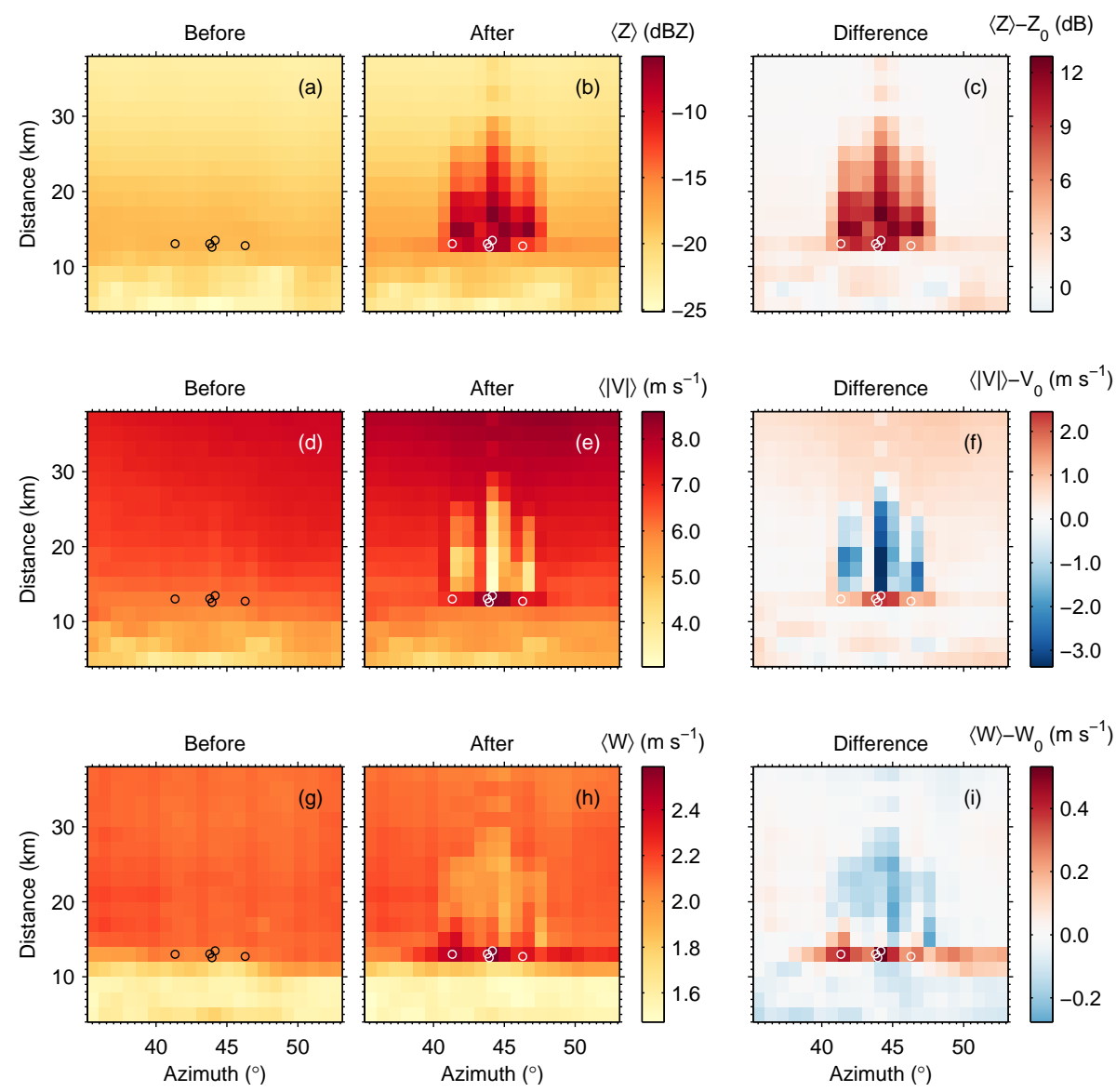

Figure 2. The columns to the left and in the middle show average reflectivity, $\langle Z\rangle$; average absolute radial velocity, $\langle|V|\rangle$; and average spectrum width, $\langle W\rangle$, before and after the construction of the Brunsmo wind farm. The right-hand column shows the difference (after-before). The locations of the wind turbines are shown with black or white circles. The impact of the wind turbines is seen for all spectral moments as changes to their average value. The impact of the wind turbines extends to radar cells both cross- and downrange from the wind farm.

the radar line of sight for the scan with the lowest tilt angle $\left(\theta=0.5^{\circ}\right)$. Three of the five wind turbines are located within the same radar cell (azimuth gate 52, near $44^{\circ}$ azimuth).

\section{Methods and results}

\subsection{Wind turbine impact on a single radar scan}

One way to investigate the impact of wind turbines on Doppler weather radar data is to compare the average values of the spectral moments before and after the construction of a wind turbine. The differences between these average values provide an estimate of the impact of the wind turbine.

Reflectivity, $Z$, and spectrum width, $W$, are well suited for calculating average values, but radial velocity measurements, $V$, can be either positive or negative, depending on the wind direction relative to the radar. Since we are interested in finding an estimate of the wind turbine impact on $V$, the influence of the wind direction was minimised by studying the absolute radial velocity, $|V|$.
The average values of the above-described spectral moments $(Z,|V|$, and $W)$ were calculated before the construction of the Brunsmo wind farm (January 2008-March 2010) and after the wind farm's start of operations (May 2010 December 2013). In order to investigate the areal extent of the impact of the wind turbines, multiple radar cells (range: 4-38 km; azimuth: $35-53^{\circ}$ ) in the vicinity of the Brunsmo wind farm were analysed using data from the scan with the lowest tilt angle $\left(\theta=0.5^{\circ}\right)$.

Undetected reflectivity measurements (see Sect. 2) were included when calculating the average value of $Z$ since these measurements carry actual information. However, as undetected measurements for $V$ and $W$ do not contain reliable information, such measurements were excluded when calculating the average values of $|V|$ and $W$. Invalid measurements were excluded for all spectral moments.

Figure $2 \mathrm{a}$ and $\mathrm{b}$ shows the average reflectivity, $\langle Z\rangle$, before and after the construction of the Brunsmo wind farm, respectively. Figure 2a shows that $\langle Z\rangle$ was uniform over the whole analysed area (especially in azimuth) before the con- 

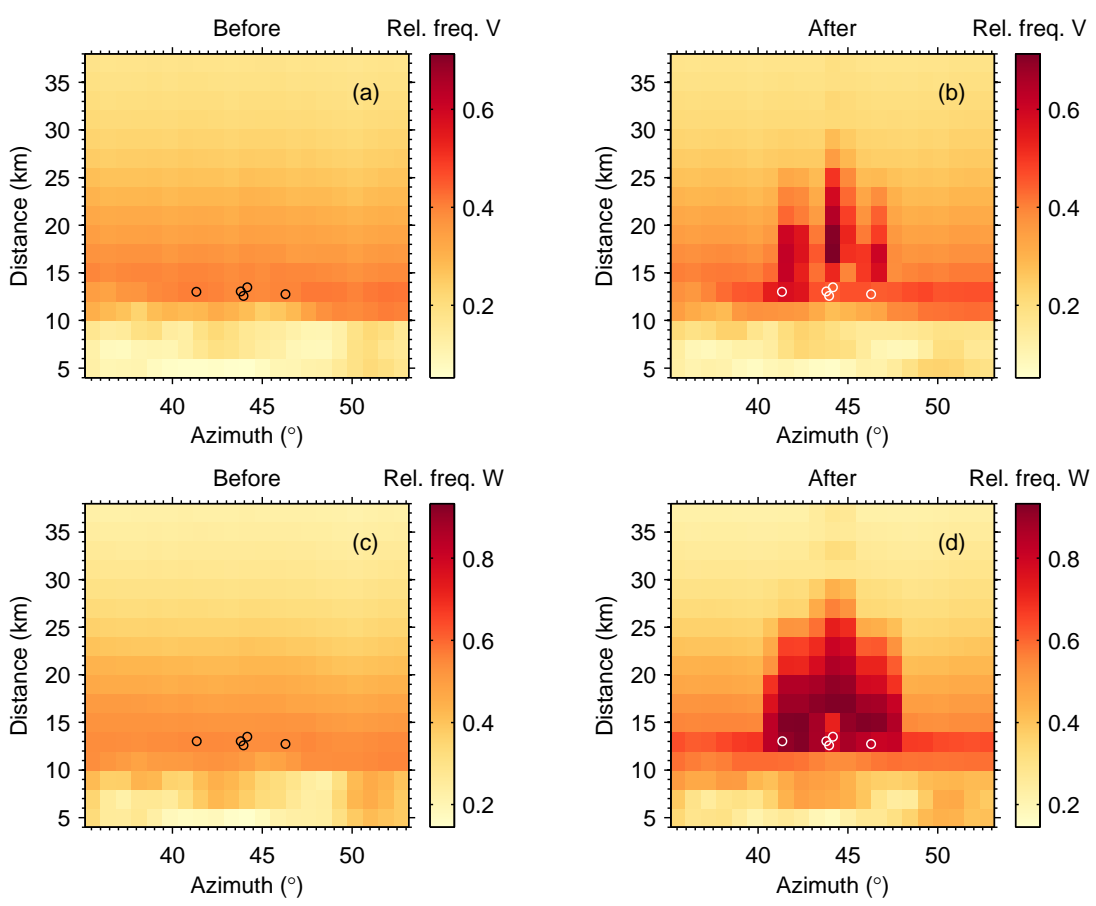

Figure 3. Relative frequency of real (detected and valid) measurements of radial velocity, $V$, and spectrum width, $W$, before and after the construction of the Brunsmo wind farm. The locations of the wind turbines are shown with black or white circles. The wind turbines are seen to increase the frequency of real measurements of $V$ and $W$, both at the location of the wind turbines as well as cross- and downrange from the wind farm.

struction of the wind farm, with only small variations in amplitude. However, after the construction of the wind farm Fig. $2 b$ shows that $\langle Z\rangle$ increases in amplitude, not only in the radar cells in which the wind turbines are located but also in several radar cells downrange of the wind turbines. One of the highest values of $\langle Z\rangle$ is seen in the radar cell in which three wind turbines are located. The average reflectivity in this radar cell is $\langle Z\rangle \approx-6 \mathrm{dBZ}$, which should be compared to $\langle Z\rangle \approx-18 \mathrm{dBZ}$ in the same radar cell before the wind turbines were built. For convenience, Fig. $2 \mathrm{c}$ shows the difference between $\langle Z\rangle$ after and before the construction of the wind farm.

Tails of increased reflectivity downrange of wind turbines have been noted in several other works (see, e.g., Crum et al., 2008; Isom et al., 2009; Haase et al., 2010; Vogt et al., 2011; Norin and Haase, 2012). Such tails are believed to be caused by multiple scattering effects (scattering between multiple turbines and/or scattering between turbine and ground) (Isom et al., 2009; Vogt et al., 2011; Kong, 2014). The tails of increased reflectivity seen in Fig. $2 b$ and $c$ extend more than $20 \mathrm{~km}$ downrange of the wind turbines. The amplitude of $\langle Z\rangle$ in the tails is seen to reach a maximum shortly behind the wind turbines, after which it decreases with increasing distance.

Figure $2 \mathrm{~d}$ and e shows the average absolute radial velocity, $\langle|V|\rangle$, before and after the construction of the wind farm, respectively. Before the construction of the wind farm it is seen from Fig. 2d that the amplitude of $\langle|V|\rangle$ increases with range from the radar but is very homogeneous in azimuth. Figure $2 \mathrm{e}$ shows that after the wind farm became operational the amplitude of $\langle|V|\rangle$ increased in radar cells containing wind turbines. However, radar cells downrange from the wind turbines show a decrease in amplitude. The largest value of $\langle|V|\rangle$ is found in the radar cell containing three wind turbines, where $\langle|V|\rangle>8.5 \mathrm{~m} \mathrm{~s}^{-1}$. In the radar cell behind the three turbines the smallest value of $\langle|V|\rangle$ is found, $\langle|V|\rangle \approx 3 \mathrm{~m} \mathrm{~s}^{-1}$. Before the construction of the wind farm the values in both these radar cells were $\langle|V|\rangle \approx 6 \mathrm{~m} \mathrm{~s}^{-1}$. Figure $2 \mathrm{f}$ shows the difference between $\langle|V|\rangle$ after and before the construction of the wind farm.

Figure $2 \mathrm{~g}$ and $\mathrm{h}$ shows the average spectrum width, $\langle W\rangle$, before and after the construction of the wind farm, respectively. In these figures it can be seen that after the construction of the wind farm a slight increase in $\langle W\rangle$ appears in the radar cells containing wind turbines, whereas a decrease in $\langle W\rangle$ occurs over a large area cross- and downrange of the wind turbines. The average spectral width increased from $\langle W\rangle \approx 2.0 \mathrm{~m} \mathrm{~s}^{-1}$ to $\langle W\rangle>2.5 \mathrm{~m} \mathrm{~s}^{-1}$ at the wind turbines, whereas behind the turbines a decrease down to $\langle W\rangle \approx$ $1.8 \mathrm{~m} \mathrm{~s}^{-1}$ can be seen. Decreased levels of $\langle W\rangle$ can be seen up to $20 \mathrm{~km}$ behind the wind turbines. The difference between $\langle W\rangle$ after and before the construction of the wind farm is shown in Fig. $2 \mathrm{i}$. 

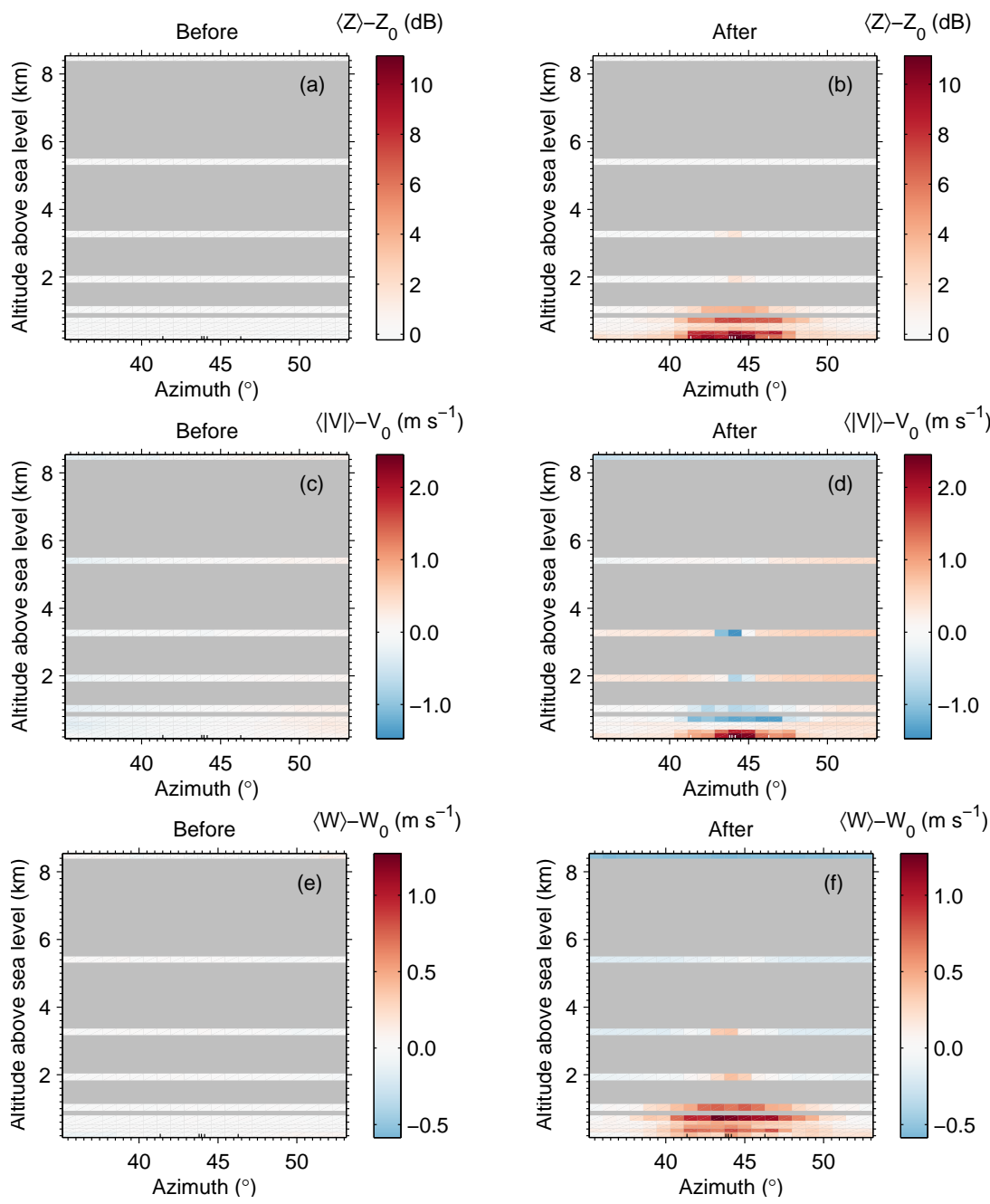

Figure 4. Difference in average reflectivity, $\langle Z\rangle-Z_{0}$; difference in average absolute radial velocity, $\langle|V|\rangle-V_{0}$; and difference in average spectrum width, $\langle W\rangle-W_{0}$, for all tilt angles $\left(0.5^{\circ} \leq \theta \leq 40^{\circ}\right)$ before and after the construction of the Brunsmo wind farm. For each scan, $Z_{0}$, $V_{0}$, and $W_{0}$ were calculated as the mean value in azimuth (for the azimuth gates shown in the figure) of the corresponding spectral moment before the construction of the wind farm. For every scan, the data shown were taken from the range bin corresponding to the location of the wind turbines. For scans with higher tilt angles $\left(2.5^{\circ} \leq \theta \leq 40^{\circ}\right)$ the average values of the two range bins nearest the wind turbines were used since for these scans the range resolution is 2 times that of the scans with lower tilt angles. The locations of the wind turbines are shown on the bottom of each plot as black or white vertical lines. The wind turbines are only in the radar line of sight for the scan with the lowest tilt angle but are nevertheless seen to have an impact on scans with higher tilt angles.

The average values of $V$ and $W$ are based on real measurements, i.e. measurements that are neither undetected nor invalid. In addition to their average values it is also of interest to study their frequency of occurrence. Complementary to the results presented in Fig. 2 the relative frequency of occurrence of $V$ and $W$ is shown in Fig. 3.

Figure $3 \mathrm{a}$ and $\mathrm{b}$ shows the relative frequency of occurrence of $V$ before and after the construction of the Brunsmo wind farm, respectively. By comparing the two figures, it is seen that after the wind farm was constructed the relative frequency of detected radial velocity measurements increased from approximately $40 \%$ to more than $70 \%$ behind the wind turbines.
Figure $3 \mathrm{c}$ and $\mathrm{d}$ shows the relative frequency of occurrence of $W$ before and after the construction of the Brunsmo wind farm, respectively. It is seen that the presence of the wind farm led to spectral width being detected more often. The relative frequency of occurrence of $W$ increased from approximately $50 \%$ to more than $90 \%$, at and behind the wind turbines.

Together, Figs. 2 and 3 show that the construction of the Brunsmo wind farm has led to real (detected) measurements of all spectral moments occurring more frequently. The average value of $Z$ increased at and near the wind turbines, whereas $\langle|V|\rangle$ and $\langle W\rangle$ increased in radar cells located at the wind turbines but decreased behind. 


\subsection{Wind turbine impact on polar volume data}

As was shown in Fig. 1, the wind turbines in the Brunsmo wind farm are in the radar line of sight for the scans with the lowest tilt angle $\left(\theta=0.5^{\circ}\right)$. However, this calculation is based on the assumption of standard atmospheric conditions and further assumes that the extent of the radar lobe is limited by its half-power beam width. In order to investigate whether scans with higher tilt angles also are affected by the Brunsmo wind farm, data from all 10 scans in the polar volume were analysed.

Figure 4 shows the impact of the wind farm on $\langle Z\rangle,\langle|V|\rangle$, and $\langle W\rangle$ for all 10 scans in the polar volume. In Fig. 4 every scan is represented by the radar cells in which the wind turbines would be located if a vertical line from the turbines were drawn from the ground. For the higher tilt angles $\left(2.5^{\circ} \leq \theta \leq 40^{\circ}\right)$ the average values of the spectral moments from the two radar cells nearest to the wind turbines were used, since for these scans the range resolution is 2 times that of the lower scans (cf. Table 1). Furthermore, in order to clearly display the change in the spectral moments for all scans in the same figure, the mean value in azimuth (for the extent of the analysed area, 35-53 ${ }^{\circ}$ ) for every spectral moment from before the construction of the wind farm were subtracted from the measurements (both before and after the construction of the wind farm). These mean values are denoted by $Z_{0}, V_{0}$, and $W_{0}$.

Figure $4 \mathrm{a}$ and $\mathrm{b}$ shows $\langle Z\rangle-Z_{0}$ before and after the construction of the wind farm, respectively. Figure 4 a shows that before the wind farm was built $\langle Z\rangle-Z_{0}$ was homogeneous in azimuth for all scans. In Fig. $4 b$, after the construction of the wind farm, an increase in $\langle Z\rangle-Z_{0}$ can be seen in the radar cells near the location of the wind turbines for some scans. For the scan with the lowest tilt angle $\left(\theta=0.5^{\circ}\right)$ the increase is approximately $12 \mathrm{~dB}$ (cf. Fig. 2b). However, increased levels of $\langle Z\rangle-Z_{0}$ are seen not only in the lowest scan (in which the wind turbines are in the radar line of sight) but also in higher scans. From Fig. $4 \mathrm{~b}$ it is seen that the fifth $\operatorname{scan}\left(\theta=2.5^{\circ}\right)$ shows an increase of $\langle Z\rangle-Z_{0} \approx 8 \mathrm{~dB}$, which is much larger than that of the fourth scan $\left(\theta=2.0^{\circ}\right)$, where $\langle Z\rangle-Z_{0} \approx 2 \mathrm{~dB}$. This can partly be explained by the change in radar cell resolution that occurs between the four lowest scans and the six highest scans (cf. Sect. 2 and Table 1) and is discussed further in Sect. 5. A slight increase in $\langle Z\rangle-Z_{0}$ (approximately $2 \mathrm{~dB}$ ) still exists near $3 \mathrm{~km}$ altitude.

Figure $4 \mathrm{c}$ and $\mathrm{d}$ shows $\langle|V|\rangle-V_{0}$ before and after the construction of the wind farm, respectively. Before the wind farm was built, $\langle|V|\rangle-V_{0}$ was uniform in azimuth for all scans, as seen in Fig. 4c. Figure 4d shows that after the wind farm was constructed an increase in $\langle|V|\rangle-V_{0}$ exists in the radar cells near the wind turbines for the scans with the two lowest tilt angles $\left(\theta=0.5^{\circ}\right.$ and $\left.\theta=1.0^{\circ}\right)$. The largest increase in $\langle|V|\rangle-V_{0}$ is seen in the scan with the lowest tilt angle, where the increase is close to $2.5 \mathrm{~m} \mathrm{~s}^{-1}$. For higher tilt angles no change $\left(\theta=1.5^{\circ}\right.$ and $\left.\theta=2.0^{\circ}\right)$ or a decrease $\left(2.5^{\circ} \leq \theta \leq 14^{\circ}\right)$ in $\langle|V|\rangle-V_{0}$ is seen. A decrease of approximately $-1.5 \mathrm{~m} \mathrm{~s}^{-1}$ can still be seen near $3 \mathrm{~km}$ altitude, far above the wind farm.

Figure $4 \mathrm{e}$ and f shows $\langle W\rangle-W_{0}$ before and after the construction of the wind farm, respectively. As for the other two examined spectral moments, $\langle W\rangle-W_{0}$ is homogeneous in azimuth for all scans before the construction of the wind farm (see Fig. 4e), whereas increased amplitudes in $\langle W\rangle-W_{0}$ are seen in Fig. 4f, after the wind farm was built. The increase in $\langle W\rangle-W_{0}$ for the second-lowest $\operatorname{scan}\left(\theta=1.0^{\circ}\right)$ is close to $1.0 \mathrm{~m} \mathrm{~s}^{-1}$, higher than the increase for the lowest $\operatorname{scan}\left(\theta=0.5^{\circ}\right)$, which is near $0.5 \mathrm{~m} \mathrm{~s}^{-1}$. A sharp increase in $\langle W\rangle-W_{0}$ can be seen between the fourth scan $\left(\theta=2.0^{\circ}\right)$ and the fifth $\operatorname{scan}\left(\theta=2.5^{\circ}\right)$, where the change in radar cell resolution occurs. Increased values of $\langle W\rangle-W_{0}$ can be seen far above the wind farm, near $3 \mathrm{~km}$ altitude.

Figure 5 shows a cross section in range $(4-38 \mathrm{~km})$ and height $(0-4 \mathrm{~km})$ of the polar volume for azimuth gate 52 , the gate in which three wind turbines are located (near $44^{\circ}$ azimuth). The same quantities as in Fig. 4 are shown (i.e. $\langle Z\rangle-Z_{0},\langle|V|\rangle-V_{0}$, and $\left.\langle W\rangle-W_{0}\right)$.

Figure $5 \mathrm{a}$ and $\mathrm{b}$ shows $\langle Z\rangle-Z_{0}$ before and after the construction of the wind farm, respectively. In Fig. $5 b$ it is seen that, after the construction of the wind farm, increased values of $\langle Z\rangle-Z_{0}$ extend tens of kilometres downrange of the wind turbines for the lowest two tilt angles $\left(\theta=0.5^{\circ}\right.$ and $\theta=1.0^{\circ}$ ); cf. Fig. 2b. For higher tilt angles no increase in $\langle Z\rangle-Z_{0}$ downrange of the wind turbines can be seen.

Figure $5 \mathrm{c}$ and $\mathrm{d}$ shows $\langle|V|\rangle-V_{0}$ before and after the construction of the wind farm, respectively. Figure $5 \mathrm{~d}$ shows that, after the wind farm was constructed, increased values of $\langle|V|\rangle-V_{0}$ exist in the radar cells in which the wind turbines are located for the lowest two tilt angles $\left(\theta=0.5^{\circ}\right.$ and $\left.\theta=1.0^{\circ}\right)$. Downrange of the wind turbines for these tilt angles a decrease in $\langle|V|\rangle-V_{0}$ is seen. For higher tilt angles $\left(2.5^{\circ} \geq \theta \leq 14^{\circ}\right)$ a decrease in $\langle V\rangle-V_{0}$ exists at the location of the wind turbines.

Figure 5e and f shows $\langle W\rangle-W_{0}$ before and after the construction of the wind farm, respectively. Figure $5 \mathrm{f}$ shows that, after the construction of the wind farm, $\langle W\rangle-W_{0}$ increased at and above the locations of the wind turbines, for altitudes up to $3 \mathrm{~km}$. Downrange of the wind turbines a slight decrease in $\langle W\rangle-W_{0}$ is seen for the lowest tilt angle $\left(\theta=0.5^{\circ}\right)$, whereas a slight increase in $\langle W\rangle-W_{0}$ can be seen for $\theta=1.0^{\circ}$.

Supplementary to Figs. 4 and 5, animations of $\langle Z\rangle,\langle|V|\rangle$, and $\langle W\rangle$ for all 10 scans are shown in Figs. S1-S3 in the Supplement, respectively. These animations show a 3-D view of the impact the Brunsmo wind farm has on the three spectral moments. From the animations it is seen that tails of changed amplitudes of the spectral moments are only visible for the scans with the lowest two tilt angles. 

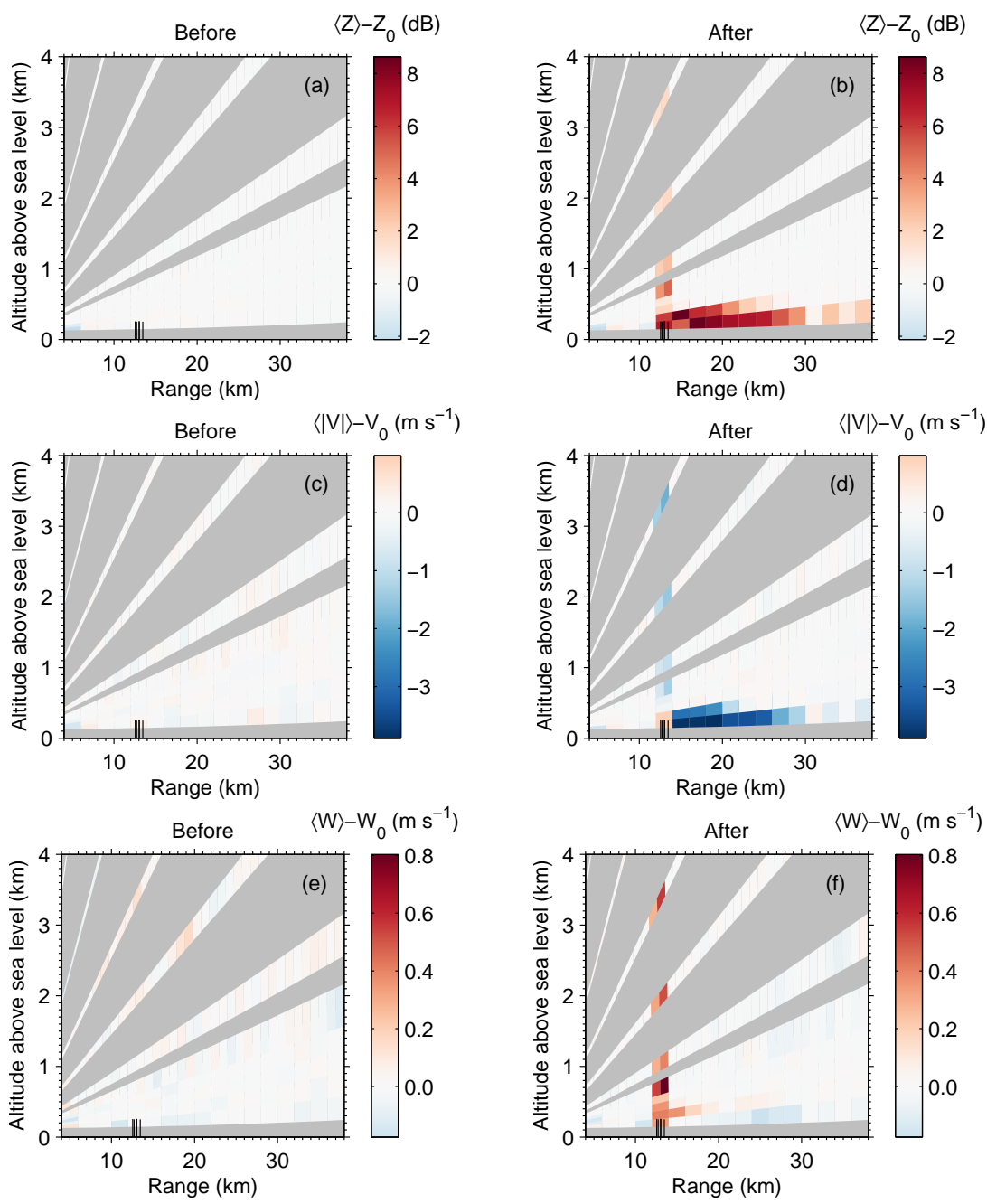

Figure 5. Difference in average reflectivity, $\langle Z\rangle-Z_{0}$; difference in average absolute radial velocity, $\langle|V|\rangle-V_{0}$; and difference in average spectrum width, $\langle W\rangle-W_{0}$, for all tilt angles $\left(0.5^{\circ} \leq \theta \leq 40^{\circ}\right)$ before and after the construction of the Brunsmo wind farm. For each scan, $Z_{0}, V_{0}$, and $W_{0}$ were calculated as the mean value in azimuth (for the azimuth gates shown in Fig. 4) of the corresponding spectral moment before the construction of the wind farm. Data were taken from azimuth gate 52 , the gate in which three wind turbines are located (near $44^{\circ}$ azimuth). The locations of the wind turbines are shown on the bottom of each plot as black vertical lines. The wind turbines are only in the radar line of sight for the scan with the lowest tilt angle but are nevertheless seen to impact scans with higher tilt angles.

\subsection{Wind turbine impact on a single radar cell}

In Sects. 4.1 and 4.2 average values of the spectral moments were compared before and after the construction of the Brunsmo wind farm. While this is a robust and simple way to illustrate the impact of wind turbines on weather radar data, these average values do not separate the weather signal from the unwanted wind turbine clutter. Hence, this method tacitly assumes that the weather signal, on average, was similar during the two measurement periods (before and after the construction of the wind farm).

In order to perform a more in-depth analysis of the impact of wind turbines on radar data, one would ideally want to know the actual, unaffected values of the weather signal at all times. A way to simulate this is to use simultaneous mea- surements from a reference radar cell, a radar cell unaffected by the wind turbines.

This technique was used by Haase et al. (2010) and Norin and Haase (2012) in their works. As reference cells they used radar cells with the same location in range and azimuth as the wind-turbine-affected radar cells, albeit from a scan with a higher tilt angle $\left(\theta=2.0^{\circ}\right)$. Furthermore, in order to remove the influence of weather, they chose to select only those measurements for which the reflectivity in the reference cell was undetected (i.e. $Z_{\text {ref }}=-30 \mathrm{dBZ}$ ). As can be seen from Fig. 4, such a choice of reference radar cells must be treated with caution since radar cells in scans from higher tilt angles may also be affected by the presence of the wind farm.

In this work a different choice of reference radar cell was used: the radar cells one radar cell up-range from the radar 


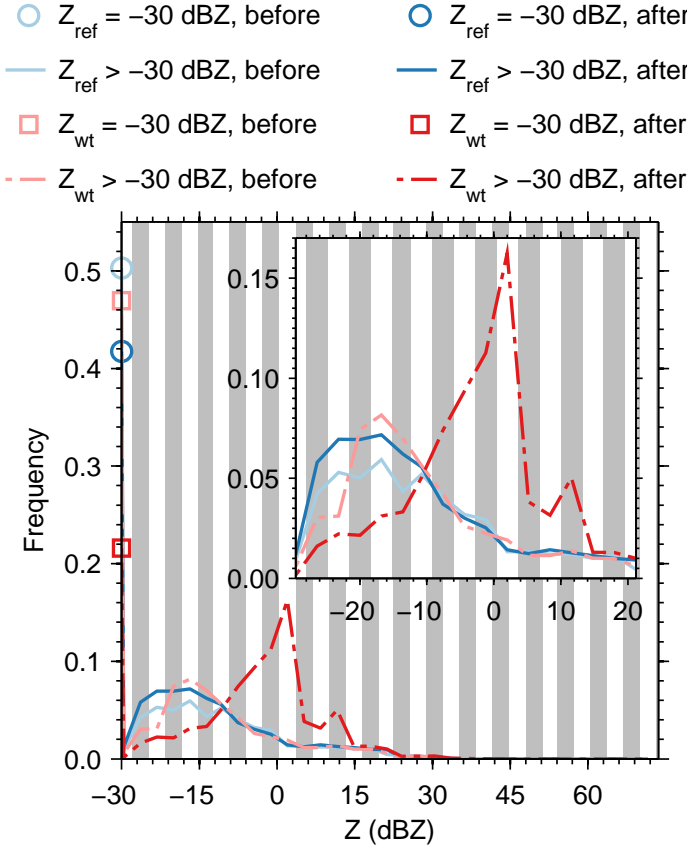

Figure 6. Relative frequency distributions of reflectivity from a reference radar cell, $Z_{\text {ref }}$, and from a radar cell in which three wind turbines are located, $Z_{\mathrm{wt}}$, before and after the construction of a wind farm, using data from the scan with the lowest tilt angle $\left(\theta=0.5^{\circ}\right)$. The grey and white backgrounds represent the bins that were used to create the distributions.

cells in which the wind turbines are located. From Fig. 2 it is seen that these radar cells are not affected by the wind farm.

In order to investigate the impact of wind turbines on a single radar cell, we chose to study data from the radar cell in which three wind turbines are located $\left(\theta=0.5^{\circ}\right.$, range cell 7 , azimuth gate 52). The corresponding reference radar cell was selected from the scan with the same tilt angle and azimuth gate albeit one range bin up-range from the wind-turbineaffected cell $\left(\theta=0.5^{\circ}\right.$, range cell 6 , azimuth gate 52).

In the analysis frequency distributions of the spectral moments $(Z, V$, and $W)$ were examined as functions of $Z_{\text {ref. }}$ In order to have sufficiently many samples for the analysis, data for $Z$ and $V$ were sorted into 35 bins.

For $Z$, one bin was used to count all measurement for which $Z=-30 \mathrm{dBZ}$ (undetected measurements) and one bin counted all invalid measurements. The remaining 33 bins were equally spaced from $Z=-29.6 \mathrm{dBZ}$ to $Z=71.6 \mathrm{dBZ}$. For $V$, one bin was used to count all undetected measurements and one bin counted all invalid measurements. The remaining 33 bins were equally spaced from $V=-24 \mathrm{~m} \mathrm{~s}^{-1}$ to $V=24 \mathrm{~m} \mathrm{~s}^{-1}$.

Since measurements of $W$ only consist of four different classes (see Sect. 2) and have separate representations of undetected and invalid measurements, data for $W$ were used as they are.
Let us first examine the validity of the choice of reference radar cell. Figure 6 shows relative frequency distributions of reflectivity from the reference cell, $Z_{\text {ref }}$, and from the windturbine-affected radar cell, $Z_{\mathrm{wt}}$, before and after the construction of the Brunsmo wind farm, using data from the scan with the lowest tilt angle $\left(\theta=0.5^{\circ}\right)$. From Fig. 6 it is seen that the distributions of $Z_{\text {ref }}$, both before and after the construction of the wind farm, are similar to the distribution of $Z_{\mathrm{wt}}$ from before the wind farm was built. Some small differences exist between these distributions, but they are minor when compared to the distribution of the $Z_{\mathrm{wt}}$ after the construction of the wind farm, which is dominated by a prominent peak near $Z \approx 5 \mathrm{dBZ}$.

From Fig. 6 it is seen that neither $Z_{\text {ref }}$ nor $Z_{\mathrm{wt}}$ is normally distributed. This means that the average value of $Z$, used in Sect. 4.1 and Sect. 4.2, does not coincide with the value of $Z$ at the peak of the frequency distribution.

Distributions of reflectivity from scans with higher tilt angles, using the same choice for reference radar cells (the radar cells one radar cell up-range from the wind-turbineaffected cells), all show similar behaviour. The chosen reference radar cells were therefore judged to provide a good (albeit not perfect) representation of the weather signal in the wind-turbine-affected radar cells.

Having validated the choice of reference radar cell, a more in-depth analysis of the wind-turbine-affected radar cell from the scan with the lowest tilt angle $\left(\theta=0.5^{\circ}\right)$ could be performed. To analyse the impact of the wind turbines, frequency distributions of the spectral moments from the windturbine-affected radar cell $\left(Z_{\mathrm{wt}}, V_{\mathrm{wt}}\right.$, and $\left.W_{\mathrm{wt}}\right)$ were created as a function of the simultaneous reflectivity measurements from the reference radar cell $\left(Z_{\text {ref }}\right)$. In Fig. 7 the relative frequency distributions of $Z_{\mathrm{wt}}, V_{\mathrm{wt}}$, and $W_{\mathrm{wt}}$ are shown.

Figure $7 \mathrm{a}$ shows relative frequency distributions of $Z_{\mathrm{wt}}$ as a function of $Z_{\text {ref }}$ before the wind farm was constructed. It is seen that, as expected, the measurements of $Z_{\text {ref }}$ in general accurately represent the measurements of $Z_{\mathrm{wt}}$. For $Z_{\text {ref }} \lesssim-15 \mathrm{dBZ}$ the values of $Z_{\mathrm{wt}}$ tend to be somewhat higher than $Z_{\text {ref }}$ (cf. Fig. 6). In Fig. 7b the same relative frequency distributions are shown, albeit this time for data gathered after the construction of the wind farm. For $Z_{\text {ref }} \gtrsim 5 \mathrm{dBZ}$ it is seen that $Z_{\text {ref }}$ provides a good representation of $Z_{\mathrm{wt}}$, whereas for $Z_{\text {ref }} \lesssim 5 \mathrm{dBZ}$ the situation is different. For all values of $Z_{\text {ref }} \lesssim 5 \mathrm{dBZ}$ the distributions of $Z_{\mathrm{wt}}$ exhibit a peak at $Z_{\mathrm{wt}} \approx 5 \mathrm{dBZ}$. This reflectivity value, $Z \approx 5 \mathrm{dBZ}$, is the most frequent reflectivity value generated by the wind turbines. When the reflectivity value from the actual weather is smaller than this value, the wind turbines effectively hide the weather signal. When the weather signal is larger than the wind turbine clutter, the reflectivity value approaches that of the reference cell.

Figure $7 \mathrm{c}$ shows the relative frequency distributions of $V_{\mathrm{wt}}$ as a function of $Z_{\mathrm{ref}}$ before the wind farm was constructed. From Fig. 7c it is seen that the distributions of $V_{\mathrm{wt}}$ have their maxima near $V_{\mathrm{wt}} \approx \pm 5 \mathrm{~m} \mathrm{~s}^{-1}$, regardless of the 

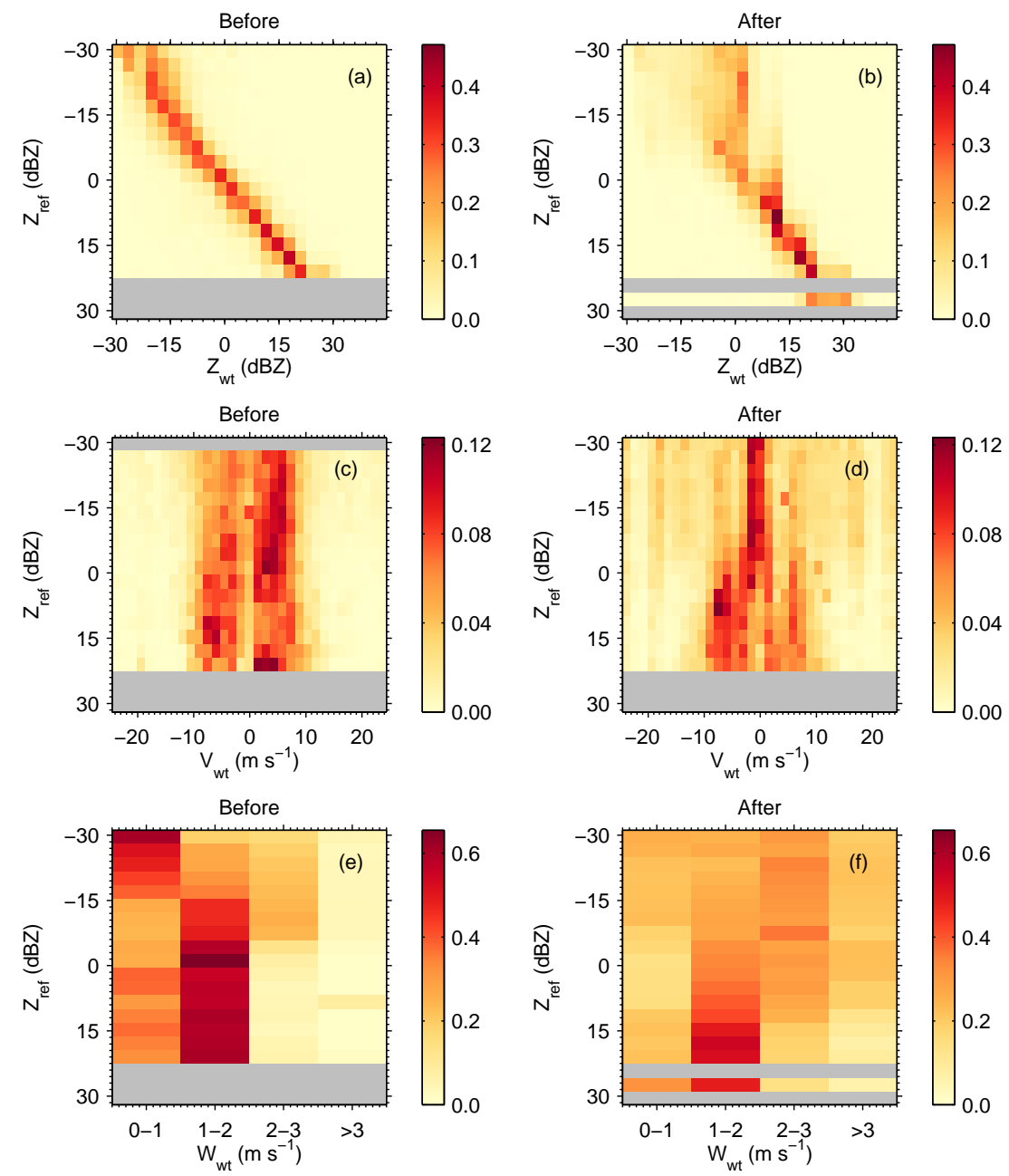

Figure 7. Relative frequency distributions of reflectivity, $Z_{\mathrm{wt}}$; radial velocity, $V_{\mathrm{wt}}$; and spectrum width, $W_{\mathrm{wt}}$, from a radar cell in which three wind turbines are located as a function of reflectivity from a reference radar cell, $Z_{\text {ref }}$, using data from the scan with the lowest tilt angle $\left(\theta=0.5^{\circ}\right)$. Panels on the left-hand side $(\mathbf{a}, \mathbf{c}$, and $\mathbf{e})$ show relative frequency distributions before the wind farm was constructed, and panels to the right $(\mathbf{b}, \mathbf{d}$, and $\mathbf{f})$ show the corresponding distributions after the wind farm start of operations. For $Z_{\text {ref }} \gtrsim 5 \mathrm{dBZ}$ the distributions of $Z_{\mathrm{wt}}, V_{\mathrm{wt}}$, and $W_{\mathrm{wt}}$ are similar before and after the construction of the wind farm. However, for $Z_{\mathrm{ref}} \lesssim 5 \mathrm{dBZ}$ the distributions before and after the construction of the wind farm look different.

value of $Z_{\text {ref. }}$ Figure $7 \mathrm{~d}$ shows the same distributions, albeit for data recorded after the construction of the wind farm. For $Z_{\mathrm{ref}} \gtrsim 5 \mathrm{dBZ}$ the distributions of $V_{\mathrm{wt}}$ are similar to those shown in Fig. 7c, but for smaller values of $Z_{\text {ref }}$ the distributions of $V_{\mathrm{wt}}$ look different. For $Z_{\mathrm{ref}} \lesssim 5 \mathrm{dBZ}$ the distributions of $V_{\mathrm{wt}}$ all have their maxima at $V_{\mathrm{wt}} \approx 0 \mathrm{~m} \mathrm{~s}^{-1}$. Much as for $Z_{\mathrm{wt}}$, for $Z_{\mathrm{ref}} \gtrsim 5 \mathrm{dBZ}$ the distributions of $V_{\mathrm{wt}}$ approach the corresponding distributions with data from before the construction of the wind farm.

For $Z_{\mathrm{ref}} \lesssim 5 \mathrm{dBZ}$, the frequency distribution of $V_{\mathrm{wt}}$ was spread over almost all velocity bins, resulting in an increase in $\left\langle\left|V_{\mathrm{wt}}\right|\right\rangle$. However, when extending the analysis to radar cells downrange of the wind turbines, it was found that the frequency distribution of $V_{\mathrm{wt}}$ was concentrated to the low- velocity bins, resulting in a decrease in $\left\langle\left|V_{\mathrm{wt}}\right|\right\rangle$. A possible reason for this is discussed in Sect. 5 .

For comparison a wind rose for the period of study (20082013), together with the distribution of wind speed, is shown in Fig. 10. The measurements of wind speed and wind direction for this figure come from an automatic weather station $\left(56.2619^{\circ} \mathrm{N}, 15.2742^{\circ} \mathrm{E}\right)$, located approximately $21 \mathrm{~km}$ to the west of the weather radar. The wind speed measurements have a resolution of $1 \mathrm{~m} \mathrm{~s}^{-1}$ and were available at most once per hour during the period of study.

Figure $7 \mathrm{e}$ shows the relative frequency distributions of $W_{\mathrm{wt}}$ as a function of $Z_{\text {ref }}$ before the wind farm was constructed. From Fig. 7e it is seen that the distributions of $W_{\mathrm{wt}}$ vary depending on the value of $Z_{\text {ref. }}$. For $Z_{\text {ref }} \lesssim-15 \mathrm{dBZ}$, the distributions of $W_{\mathrm{wt}}$ peak for $W_{\mathrm{wt}}=0-1 \mathrm{~m} \mathrm{~s}^{-1}$, whereas for 

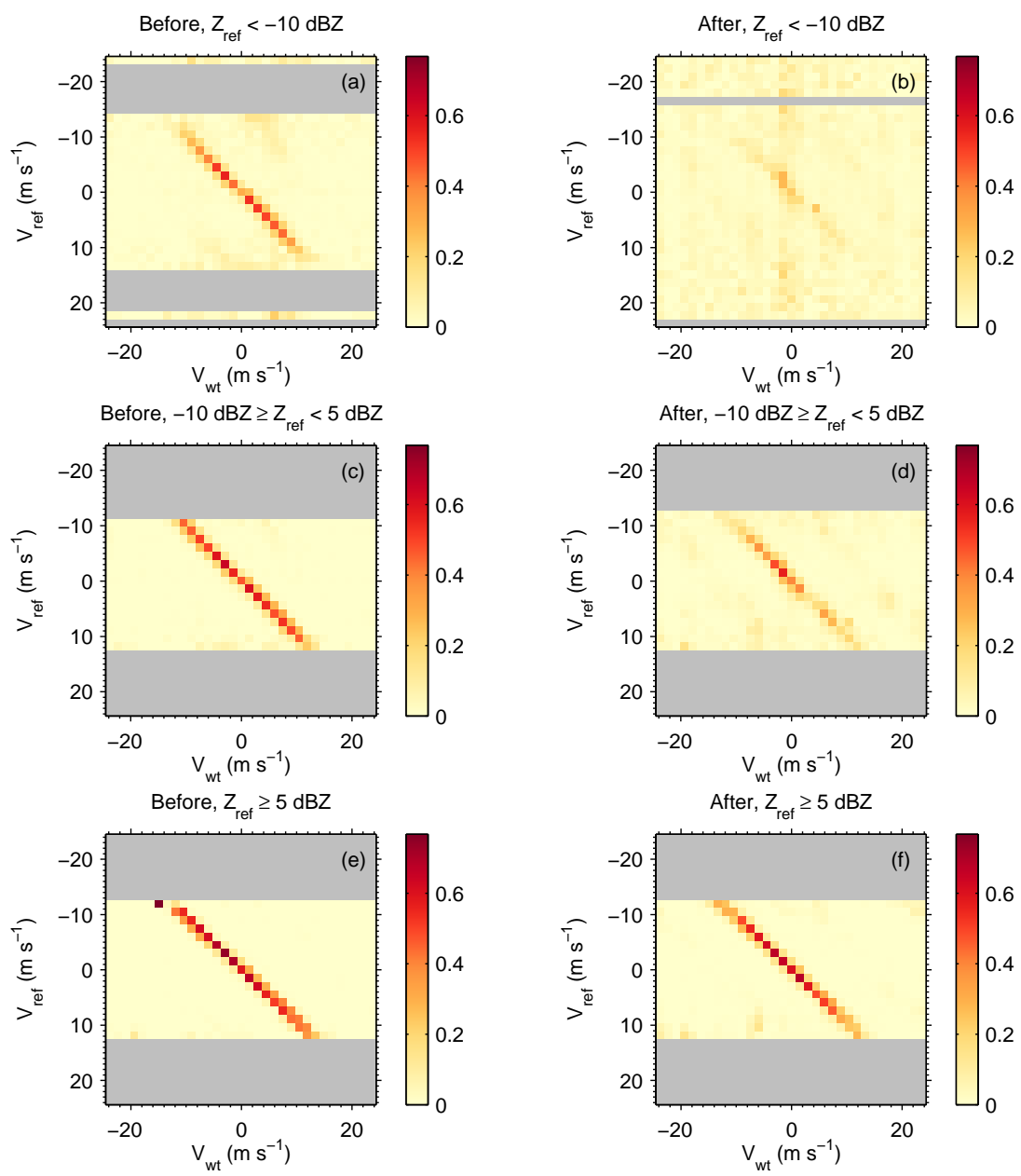

Figure 8. Relative frequency distributions of radial velocity from a radar cell in which three wind turbines are located, $V_{\mathrm{wt}}$; as a function of radial velocity, $V_{\text {ref }}$; and reflectivity, $Z_{\text {ref }}$, from a reference radar cell. Data were taken from the scan with the lowest tilt angle $\left(\theta=0.5^{\circ}\right)$. Panels on the left-hand side (a, $\mathbf{c}$, and e) show relative frequency distributions of $V_{\mathrm{wt}}$ for $Z_{\text {ref }}<-10 \mathrm{dBZ},-10 \mathrm{dBZ} \geq Z_{\mathrm{ref}}<5 \mathrm{dBZ}$, and $Z_{\text {ref }} \geq 5 \mathrm{dBZ}$, respectively, before the construction of the wind farm. Panels on the right-hand side (b, d, and f) show the corresponding distributions, using data obtained after the construction of the wind farm. In (b), for $Z_{\text {ref }}<-10 \mathrm{dBZ}$, almost no correlation exists between $V_{\mathrm{wt}}$ and $V_{\text {ref }}$, but it is clear that the correlation improves for increasing values of $Z_{\text {ref }}(\mathbf{d}$ and $\mathbf{f})$.

$Z_{\text {ref }} \gtrsim-15 \mathrm{dBZ}$ the distributions of $W_{\mathrm{wt}}$ have their maxima for $W_{\mathrm{wt}}=1-2 \mathrm{~m} \mathrm{~s}^{-1}$. From Fig. $7 \mathrm{f}$ it is seen that after the construction of the wind farm the distributions of $W_{\mathrm{wt}}$ are evenly spread out for $Z_{\text {ref }} \lesssim-5 \mathrm{dBZ}$. For larger reflectivity values the distributions of $W_{\text {wt }}$ gradually approach those before the wind farm was built.

From Fig. 7 it is clear that competition between the weather signal and the wind turbine clutter exists. Once the strength of the weather echoes exceeds that of the wind turbine clutter, all spectral moments are seen to approach their respective values of the reference cell.

\subsection{Improvement of the weather signal}

In Fig. 7c and d it was shown that measurements of $V_{\mathrm{wt}}$ approached the values of the reference cell for $Z_{\text {ref }} \gtrsim 5 \mathrm{dBZ}$.
Another way to see how $V_{\mathrm{wt}}$ approaches its true value for increasing values of $Z_{\text {ref }}$ is shown in Fig. 8. In this figure the relative frequency distributions of $V_{\mathrm{wt}}$ are shown as functions of $V_{\text {ref }}$ and $Z_{\text {ref. }}$ Figure $8 \mathrm{a}$, c, and e shows the distributions of $V_{\mathrm{wt}}$ as a function of $V_{\text {ref }}$ for $Z_{\text {ref }}<$ $-10 \mathrm{dBZ},-10 \mathrm{dBZ} \geq Z_{\text {ref }}<5 \mathrm{dBZ}$, and $Z_{\text {ref }} \geq 5 \mathrm{dBZ}$, respectively, using data from before the construction of the wind farm. From these figures it is seen that before the construction of the wind farm there was a strong correlation be-

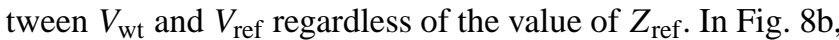
$\mathrm{d}$, and $\mathrm{f}$ the corresponding distributions are shown, albeit for data gathered after the construction of the wind farm. In Fig. 8b, where $Z_{\text {ref }}<-10 \mathrm{dBZ}$, there is almost no correlation between $V_{\mathrm{wt}}$ and $V_{\text {ref }}$, except for $V_{\text {ref }} \lesssim \pm 3 \mathrm{~m} \mathrm{~s}^{-1}$. (It is interesting to note that the cut-in speed of the wind turbines is $3.5 \mathrm{~m} \mathrm{~s}^{-1}$ (see Sect. 3), which could explain the correlation 

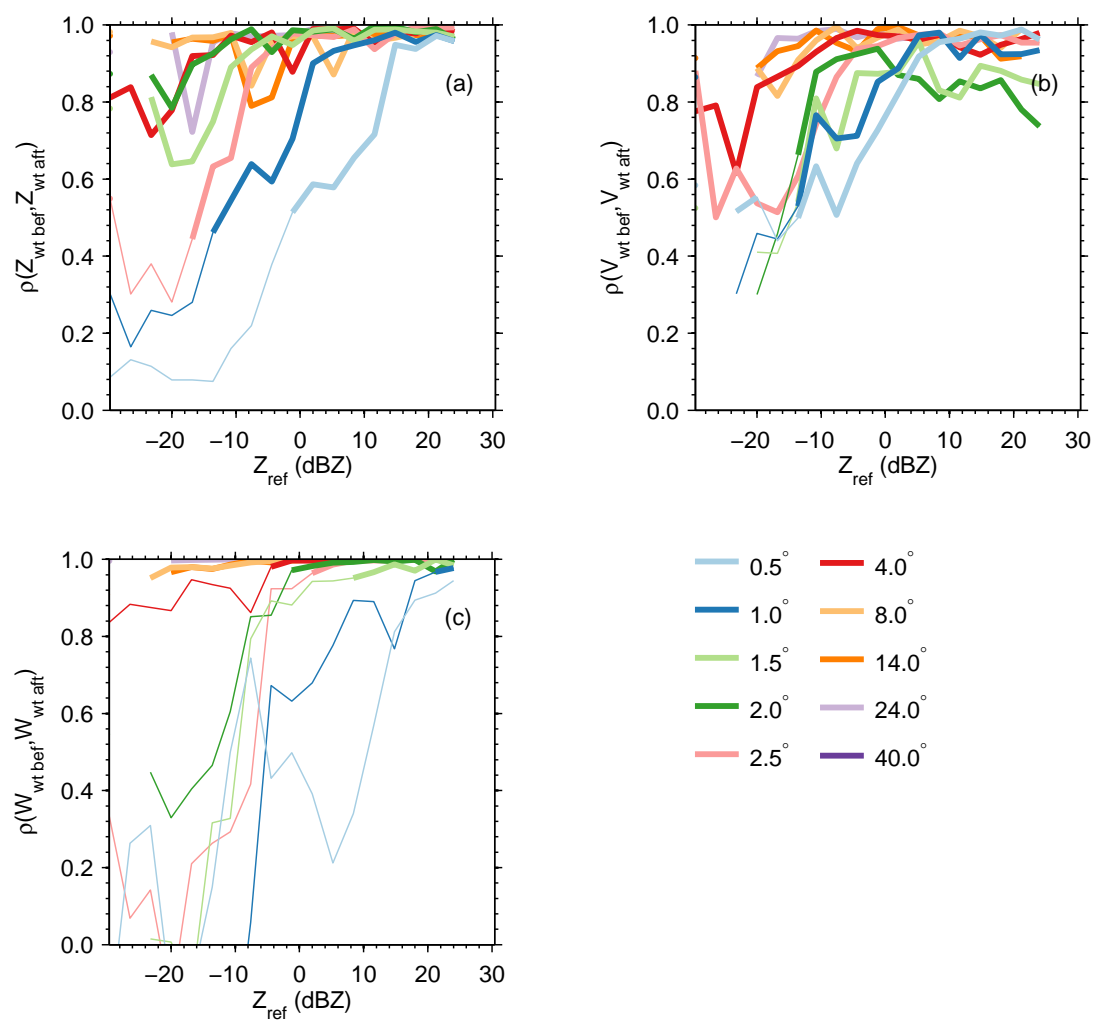

Figure 9. Correlation coefficients, $\rho$, between frequency distributions of spectral moments from a wind-turbine-affected radar cell before ( $Z_{\mathrm{wt} \text { bef }}, V_{\mathrm{wt} \text { bef }}$, and $\left.W_{\mathrm{wt} \text { bef }}\right)$ and after $\left(Z_{\mathrm{wt} \text { aft }}, V_{\mathrm{wt}}\right.$ aft , and $\left.W_{\mathrm{wt} \text { aft }}\right)$ the construction of the Brunsmo wind farm, as a function of reflectivity from a reference radar cell, $Z_{\text {ref }}$, for all tilt angles. The correlation of the spectral moments recovers for higher values of $Z_{\text {ref }}$ (increasing influence of the weather signal) and for higher tilt angles (decreasing influence of the wind farm). Correlations significant on the $p<0.05$ level are drawn with thick lines.

for $V_{\text {ref }} \lesssim \pm 3 \mathrm{~m} \mathrm{~s}^{-1}$.) In Fig. 8d the correlation between $V_{\mathrm{wt}}$ and $V_{\text {ref }}$ is seen to increase for $-10 \mathrm{dBZ} \geq Z_{\text {ref }}<5 \mathrm{dBZ}$, and for $Z_{\text {ref }} \geq 5 \mathrm{dBZ}$, shown in Fig. 8f, it is as strong as before the construction of the wind farm.

As was shown in Fig. 7, the values of all spectral moments are seen to approach those of the reference cell for increasing values of $Z_{\text {ref. }}$. A way to quantitatively analyse this change is to calculate the correlation coefficient between the distributions of the spectral moments before and after the construction of the wind farm, as a function of $Z_{\text {ref. This analysis was }}$ performed for all 10 scans in the polar volume. The windturbine-affected radar cells were represented by the radar cells with azimuth gate 52 and the range cell in which the wind turbines would be located if a vertical line were drawn from the ground. The corresponding reference cells were selected from the same azimuth gate but one radar cell closer to the radar (cf. Sect. 4.3). Correlation coefficients were only calculated for distributions for which more than 300 measurements existed. The results of the analyses for the three spectral moments $(Z, V$, and $W)$ for all 10 scans in the polar volume are shown in Fig. 9.

Figure 9a shows the correlation coefficient, $\rho$, between the distribution of $Z$ at the wind turbines, before $\left(Z_{\mathrm{wt}}\right.$ bef $)$ and af- ter $\left(Z_{\mathrm{wt}}\right.$ aft $)$ the construction of the wind farm, as a function of $Z_{\text {ref }}$ for all scans in the polar volume. The correlation coefficient, $\rho\left(Z_{\mathrm{wt} \text { bef }}, Z_{\mathrm{wt} \text { aft }}\right)$, is seen to increase for increasing values of $Z_{\text {ref }}$ (i.e. for increasing influence of the weather signal) and also for higher tilt angles (i.e. for decreasing influence of the wind farm). However, for $Z_{\text {ref }}<-5 \mathrm{dBZ}$ the correlation coefficient for the fifth scan $\left(\theta=2.5^{\circ}\right.$, the lowest scan using the higher radar cell resolution) is lower than for two scans with lower tilt angles $\left(\theta=1.5^{\circ}\right.$ and $\left.\theta=2.0^{\circ}\right)$. This can partly be explained by the changes in radar cell resolution (cf. Sect. 2 and Sect. 5). That the fifth scan is more affected by the wind farm than some of the lower scans can also be seen in Figs. 4 and 5, as well as in Fig. S1 in the Supplement.

Figure $9 \mathrm{~b}$ shows the correlation coefficient, $\rho$, between the distribution of $V$ at the wind turbines, before $\left(V_{\mathrm{wt}}\right.$ bef $)$ and after $\left(V_{\mathrm{wt}}\right.$ aft $)$ the construction of the wind farm, as a function of $Z_{\text {ref }}$ for all scans in the polar volume. In Fig. $9 \mathrm{~b}$ it is again seen that the correlation coefficient, $\rho\left(V_{\mathrm{wt} \text { bef }}, V_{\mathrm{wt} \text { aft }}\right)$, increases for increasing values of $Z_{\text {ref }}$ as well as for higher tilt angles. However, the use a higher radar cell resolution $\left(\theta \geq 2.5^{\circ}\right)$ seems to have a smaller negative impact on the improvement of $V_{\mathrm{wt}}$ than for $Z_{\mathrm{wt}}$. 

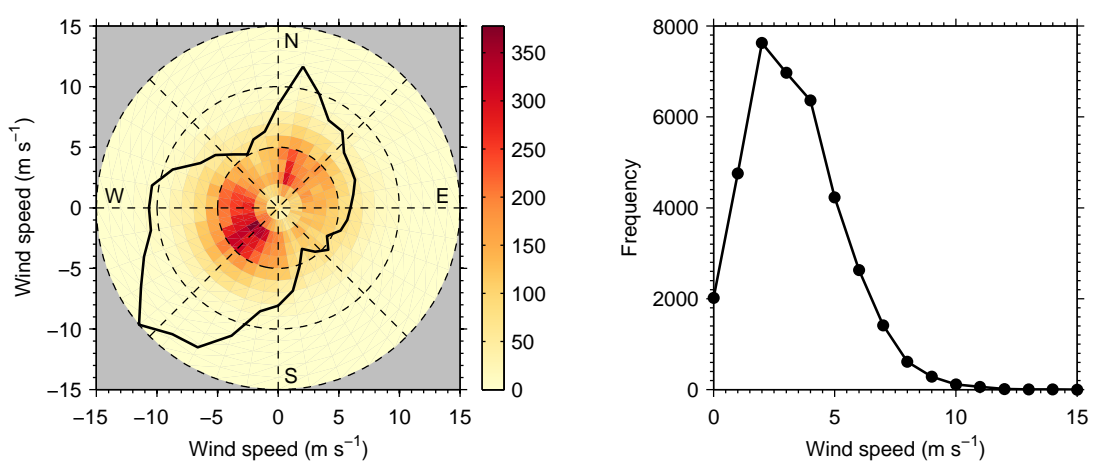

Figure 10. Wind rose showing the wind speed and wind direction using hourly data from an automatic weather station located approximately $21 \mathrm{~km}$ to the west of the weather radar for the period April 2010-December 2013. The figure to the left shows the distribution of wind speed and wind direction. The solid black line shows the wind direction for all wind speeds. The figure to the right shows the distribution of wind speed for all wind directions.

Figure 9c shows the correlation coefficient, $\rho$, between the distribution of $W$ at the wind turbines, before $\left(W_{\mathrm{wt} \text { bef }}\right)$ and after $\left(W_{\mathrm{wt}}\right.$ aft $)$ the construction of the wind farm, as a function of $Z_{\text {ref }}$ for all scans in the polar volume. As for $Z$ and $V$, the correlation coefficient for $W, \rho\left(W_{\mathrm{wt} \text { bef }}, W_{\mathrm{wt}} \mathrm{aft}\right)$, increases for increasing values of $Z_{\text {ref }}$ and also for higher tilt angles. For the scans with the lowest tilt angle $\left(\theta=0.5^{\circ}\right)$ a correlation greater than 0.9 is only achieved for $Z_{\text {ref }}>15 \mathrm{dBZ}$. Since $W$ is limited to four classes (see Sect. 2), fewer values of the correlation coefficient are statistically significant compared to the other spectral moments.

Figures 7 and 8 demonstrate that the values of all spectral moments approach those of the reference cell when the weather signal is stronger than the wind turbine clutter. Figure 9 shows that this effect can be seen for all tilt angles. However, in order to quantitatively determine the impact of a radar cell for a certain tilt angle, data should be examined more carefully, for example as described in Sect. 4.3.

\section{Discussion}

Some of the results presented in the previous sections require further discussion. Here, we first examine the changes in the average values of the spectral moments. Secondly, the sudden increase in reflectivity occurring between the fourth and the fifth scan is investigated. Thirdly, possible explanations of the impact seen on spectral moments far above the wind farm are discussed.

Let us first examine the changes in the average values of the spectral moments. Figures 2 and 3 showed that the impact of the Brunsmo wind farm on spectral moments from the scan with the lowest tilt angle extends up to $20 \mathrm{~km}$ behind the wind turbines. As mentioned in Sect. 4.1, tails of increased reflectivity downrange of wind turbines are believed to be caused by multiple scattering effects (scattering between multiple turbines and/or scattering between turbine and ground) (Isom et al., 2009; Vogt et al., 2011; Kong,
2014). A wind-turbine-scattered radar signal, shown to occur behind the wind turbines, has evidently experienced a time delay, likely caused by multiple scattering, whereas a signal shown to occur at the location of the wind farm is the result of direct scattering off the turbines. At the location of the wind farm the impact on $\langle Z\rangle$ should therefore always be positive (or negligible if in the presence of a strong weather signal). Behind the wind farm, competition may exist between blockage, leading to a decrease in $\langle Z\rangle$, and multiple scattering effects, which would lead to an increase in $\langle Z\rangle$. For the Brunsmo wind farm, examined in this work, it is clear that the net effect is an increase in $\langle Z\rangle$.

In Fig. 2 it was shown that both average absolute radial velocity, $\langle|V|\rangle$, and average spectrum width, $\langle W\rangle$, show an increase at the location of the wind turbines. If the received radar signal is dominated by scattering off one or more moving wind turbine blades, a large and variable value in $|V|$ would be expected, consistent with the observations (cf. Fig.7d). A signal composed of several frequency components of similar strength, for example generated by scattering off different locations on a single blade, would give rise to a large value of $W$.

Behind the wind turbines, however, $|V|$ and $W$ show a decrease in their average values. If the main contribution to the received radar signal originated from multiple scattering off stationary parts of the wind turbine (e.g. scattering between the tower and the ground), the resulting frequency spectrum would have a narrow peak, centred around zero frequency shift. For such a frequency spectrum an increase in $\langle Z\rangle$ together with small values in $\langle|V|\rangle$ and $\langle W\rangle$ would follow, consistent with the observations. To validate this hypothesis, in-phase (I) and quadrature (Q) measurements would need to be sampled so that individual frequency spectra could be generated and examined. Unfortunately, the Swedish weather radars lack such capability.

The second result from the previous sections worth discussing is the sudden increase in $\langle Z\rangle$ occurring between the 
fourth and the fifth scan, seen in Figs. 4 and 5. This increase can be explained by the way the Swedish radars are configured to perform their measurements. As described in Sect. 2, the radar cells from the four lowest scans use a lower resolution in both range and azimuth. A wind-turbine-affected radar cell (consisting of 12 range bins) can have one or more unaffected range bins. Since radar cells from the four lowest scans have a lower range resolution, the impact on these cells is expected to be lower than (or at most equal to) those from the higher scans. For example, a wind turbine located in the centre of a $2 \mathrm{~km}$ wide radar cell would have an impact on the last six range bins of that radar cell. However, all 12 range bins from a $1 \mathrm{~km}$ wide radar cell would be affected, and that radar cell would register a higher value in $\langle Z\rangle$ compared to the radar cell using the lower range resolution.

The changes in azimuthal resolution of the radar cells can also contribute to the observed sudden increase in $\langle Z\rangle$. A lower resolution in azimuth (used by the lower scans) means that fewer measurements in a frequency spectrum will be affected by the wind turbine, leading to a smaller impact compared to measurements from the higher scans, using the higher azimuthal resolution. These hypotheses could be tested by examining individual frequency spectra from windturbine-affected radar cells using different resolutions or by changing the radar cell resolution so that it is the same for all tilt angles.

Finally, let us investigate why the wind turbines in the Brunsmo wind farm are seen to have an impact on radar measurements far above the turbines (cf. Figs. 4 and 5). That a wind farm can have a negative impact on radar data at altitudes far above the wind turbines can be due to several mechanisms. For example, Isom et al. (2009) showed that wind farms can be detected by radar sidelobes. It is, however, also conceivable that the impact could be due to anomalous propagation, i.e., bending of the radar beam due to changes in the atmospheric refractive index. A third explanation of the observed increase in reflectivity is that it is due to scattering off increased levels of dust and turbulence, generated by the wind farm. Let us examine these mechanisms one at a time.

Figure 11 shows the increase in $\langle Z\rangle$ for the different tilt angles from the radar cells in and below which three wind turbines are located. In the same figure is also shown a vertical cut of the antenna directivity. In Fig. 11 it is seen that $\langle Z\rangle$ follows the antenna pattern for the lowest four tilt angles, after which an increase in $\langle Z\rangle$ can be seen. This increase, as discussed above, is likely a result of the Swedish radars' measurement technique. For the higher tilt angles $\langle Z\rangle$ does not decrease as much as the antenna pattern does. Also, the received power (which is proportional to reflectivity) is proportional to the directivity squared. Thus the antenna directivity, shown in Fig. 11, should be squared in order provide a fair comparison to the observed impact in $\langle Z\rangle$. From Fig. 11 it is seen that detection by the radar sidelobes does not provide a complete explanation of the impact seen on the higher scans.
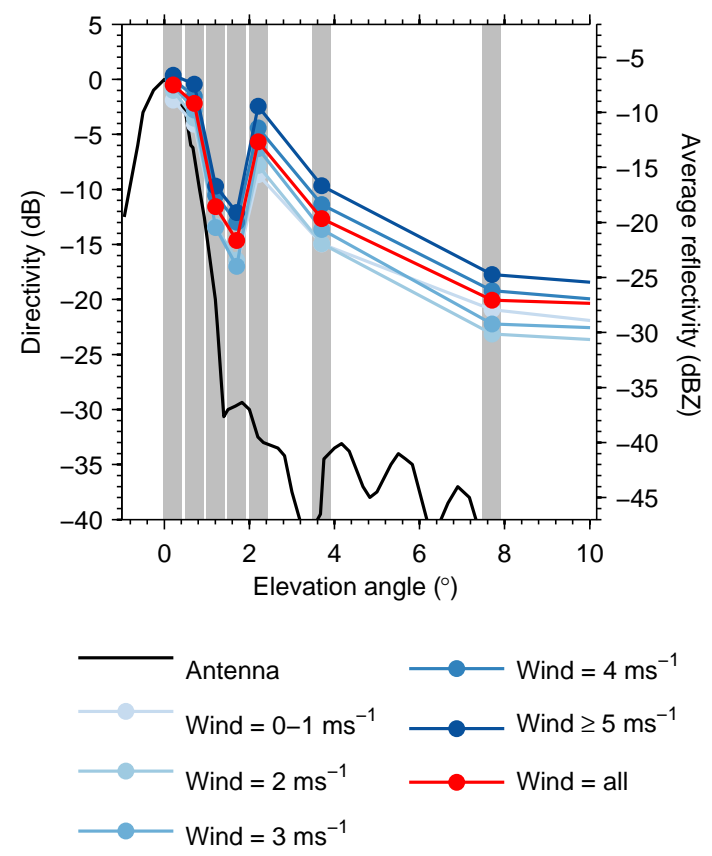

Figure 11. Increase in average reflectivity, $\langle Z\rangle$, from radar cells in and below which three wind turbines are located for different tilt angles and wind speeds. The wind speed measurements come from an automatic weather station, located approximately $21 \mathrm{~km}$ to the west of the weather radar. The black solid line shows a vertical cut of the antenna pattern. The grey areas show the angular extent of the wind turbine blades for the different tilt angles.

Another possible reason for the observed impact far above the wind farm is anomalous propagation. Anomalous propagation can sometimes result in scattering from objects on the ground, not normally seen by the radar. Such propagation conditions can be caused by temperature inversions or by a rapid decrease in water vapour content with height (see, e.g., Patterson, 2008). Temperature inversions can exist at any time of the day in Sweden during the cool season (Devasthale and Thomas, 2012), whereas such inversions most commonly occur in early morning during the warm season. A rapid decrease in water vapour content with height can occur during afternoons in summer (Bodine et al., 2011).

In order to investigate the effect of anomalous propagation, ray tracing of the radar beam was performed for the period April 2010-December 2013 (after the wind farm was built). Ray tracing of the radar beam was calculated every hour using the method proposed by Zeng et al. (2014). Vertical profiles of refractivity, needed for the calculations, were generated using data obtained from Sweden's operational numerical weather prediction model. The results, shown in Fig. 12, reveal that the changes in beam height were very small at the distance of the wind turbines. For the Brunsmo wind farm, anomalous propagation is unlikely to explain the impact seen on the higher tilt angles. 


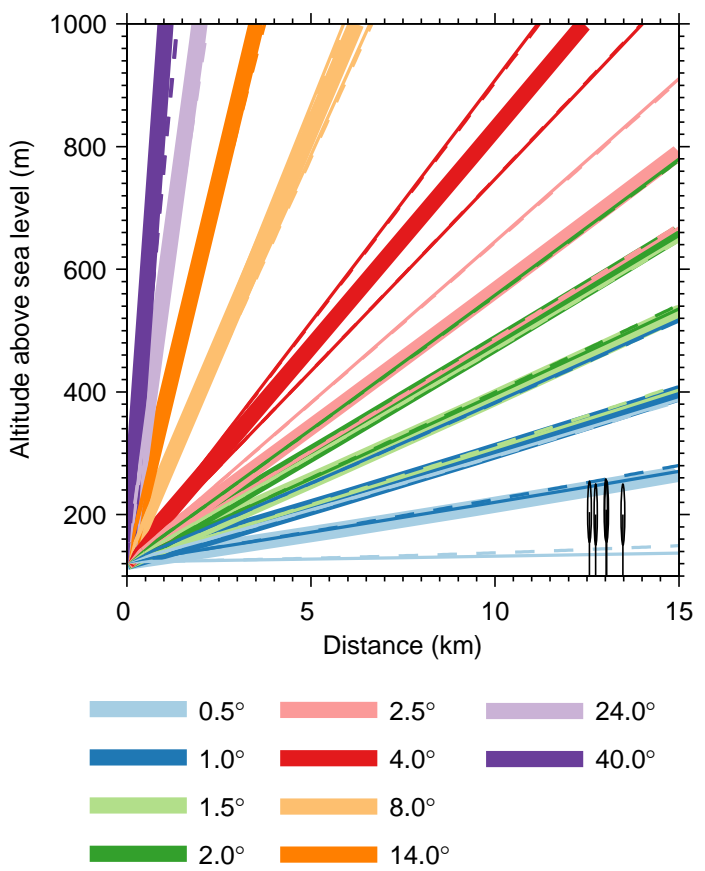

Figure 12. Beam propagation for different tilt angles calculated using ray tracing. Vertical profiles of refractivity were obtained using data from Sweden's operational NWP model. Thick solid lines show the median centre of the radar beams. Thin solid lines show the 1st and the 99th percentile of the half-power beam widths for the calculated beams. Thin dashed lines show half-power beam widths using standard propagation conditions. Wind turbines are shown in black.

The third possibility, scattering off increased levels of dust and turbulence, generated by the wind farm is difficult to examine directly. However, it is conceivable that levels of wind-turbine-generated dust and turbulence could be higher for higher wind speeds. Higher wind speeds let the turbine blades rotate faster, which in turn could lead to increased levels of dust and turbulence. Measurements of wind speed from an automatic weather station, located approximately $21 \mathrm{~km}$ to the west of weather radar Karlskrona, was shown in Fig. 10. The wind speed at the location of the automatic weather station does not necessarily coincide with the wind speed at the location of the wind farm, but the general tendency should be the same (higher wind speeds at the automatic weather station should correspond to higher wind speed at the wind farm). The wind speed measurements were divided into five bins: $0-1,2,3,4$, and $5-15 \mathrm{~m} \mathrm{~s}^{-1}$. All bins contained similar amounts of data. The average values of $\langle Z\rangle$, corresponding to the different wind speeds, are shown in Fig. 11. From this figure it is seen that higher wind speeds lead to higher values of $\langle Z\rangle$, supporting the hypothesis of increased scattering. However, the difference in $\langle Z\rangle$ between low $\left(0-1 \mathrm{~m} \mathrm{~s}^{-1}\right)$ and high $\left(5-15 \mathrm{~m} \mathrm{~s}^{-1}\right)$ wind speeds is only of the order of $5 \mathrm{~dB}$.
In summary, the observed impact on higher scans are most likely to be caused by detection of the radar sidelobes, although this does not provide a complete explanation. High wind speeds, which could lead to increased levels of dust and turbulence, also lead to an increase in reflectivity, whereas the effects of anomalous propagation seem to have a limited effect on the measurements at the Brunsmo wind farm.

\section{Summary and conclusions}

Wind turbines located in the vicinity of a Doppler weather radar can have a detrimental impact on the radar's performance. The objective of this study was to investigate the impact of wind turbines on operational Doppler weather radar data. Doppler weather radars measure three spectral moments: the radar reflectivity factor, $Z$; radial velocity, $V$; and spectrum width, $W$. In this work we have analysed the impact of wind turbines on all spectral moments, using two different approaches.

First, the average values for the three spectral moments (reflectivity, $\langle Z\rangle$; absolute radial velocity, $\langle|V|\rangle$; and spectrum width, $\langle W\rangle$ ) were computed. In this study these averages were calculated using operational radar data from long periods of time before (approximately 2.5 years) and after (approximately 3.5 years) the construction of a wind farm near radar Karlskrona in southeastern Sweden. By comparing the average values before and after, the impact of the wind farm on all spectral moments was estimated. For the wind farm studied in this work the average values of the spectral moments in the radar cells in which wind turbines are located, from the scan with the lowest tilt angle, were shown to change after the wind turbines were built; reflectivity increased from $\langle Z\rangle \approx-18 \mathrm{dBZ}$ to $\langle Z\rangle \approx-6 \mathrm{dBZ}$, the absolute radial velocity increased from $\langle|V|\rangle \approx 6 \mathrm{~m} \mathrm{~s}^{-1}$ to $\left.\langle|V|\rangle\right\rangle$ $8.5 \mathrm{~m} \mathrm{~s}^{-1}$, and the spectrum width increased from $\langle W\rangle \approx$ $2.0 \mathrm{~m} \mathrm{~s}^{-1}$ to $\langle W\rangle>2.5 \mathrm{~m} \mathrm{~s}^{-1}$. However, not only those radar cells in which the wind turbines are located were affected by the presence of the wind farm. Several radar cells both crossand downrange were also affected.

Downrange from the wind turbines, tails with increased values of $\langle Z\rangle$ were seen, visible for more than $20 \mathrm{~km}$ behind the turbines. This is believed to be caused by multiple scattering of the radar signal between rotor blades and the ground. For $\langle|V|\rangle$ and $\langle W\rangle$, tails with decreased values were observed. A possible explanation of these changes is that the dominating contribution to the radar signal received behind the wind farm originates from stationary parts of the wind turbines, but this needs to be investigated further.

In addition to the changes in values of all spectral moments in data from the scan with the lowest tilt angle it was shown that data from scans with higher tilt angles, far above the wind farm, were also affected. Increased values in $\langle Z\rangle$ and $\langle W\rangle$ and decreased values in $\langle|V|\rangle$ were seen up to $3 \mathrm{~km}$ above the wind farm. 
That a wind farm can have an impact on radar data at altitudes far above the wind turbines can be due to several reasons. Wind farms not in the line of sight of a radar can still be detected by the radar's sidelobes. Scattering off increased levels of dust and turbulence above the wind farm and anomalous propagation, i.e., bending of the radar beam, are also conceivable explanations of changed values in the spectral moments. In this work all three mechanisms were investigated. It was shown that anomalous propagation is unlikely to explain the observed changes, whereas detection by the radar sidelobes and scattering off increased levels of dust and turbulence can, at least in part, explain the observed changes.

One of the problems with wind turbine clutter is that their impact on the spectral moments is similar to that of real weather signals. To analyse the competition between the weather signal and wind turbine clutter, a second approach, using data from reference radar cells, was used. Ideally, data from a reference radar cell should, for any given measurement, show what the unaffected weather signal should be in the wind-turbine-affected radar cell. In this work the reference cells were chosen as the radar cells one radar cell uprange from the affected radar cells. Data from all three spectral moments, before and after the construction of the wind farm, were then visualised using relative frequency distributions of the spectral moment under study, as a function of $Z_{\text {ref. }}$

The results using this method revealed that the values of all spectral moments from wind-turbine-affected radar cells approach those of the reference cell (i.e. the value of the weather signal) for increasing values of $Z_{\text {ref. }}$. When precipitation gives rise to reflectivity values stronger than those caused by the wind turbines, the negative impact of the wind turbines is greatly reduced for all spectral moments.

These results suggest that the weather information from wind-turbine-affected radar cells is not always lost. One way to mitigate the impact of wind turbines could be to create conditional filters. If reflectivity from a wind-turbineaffected radar cell is larger than that caused by the wind turbine, the radar data could still be used. However, when the reflectivity is similar to or lower than the reflectivity caused by the wind turbine, caution should be applied when using radar data from any spectral moment from the wind-turbineaffected radar cells.

\section{The Supplement related to this article is available online at doi:10.5194/amt-8-593-2015-supplement.}

Acknowledgements. This work was financed by the Swedish Energy Agency, under the project VINDRAD+.

Edited by: M. Kulie

\section{References}

Bodine, D., Michaud, D., Palmer, R. D., Heinselman, P. L., Brotzge, J., Gasperoni, N., Cheong, B. L., Xue, M., and Gao, J.: Understanding Radar Refractivity: Sources of Uncertainty, J. Appl. Meteorol. Clim., 50, 2543-2560, doi:10.1175/2011JAMC2648.1, 2011.

Burgess, D. W., Crum, T. D., and Vogt, R. J.: Impacts of Wind Farms on WSR-88D Radars, in: 24th International Conference on Interactive Information and Processing Systems for Meteorology, Oceanography, and Hydrology, New Orleans, LA, United States, American Meteorological Society, paper 6B.3, 2008.

Crum, T. and Ciardi, E.: Wind Farms and the WSR-88D: An Update, Nextrad Now, 20, 17-22, 2010.

Crum, T., Ciardi, E., and Sandifer, J.: Wind Farms: Coming Soon to a WSR-88D Near You, Nexrad Now, 18, 1-7, 2008.

Department of Defense: The Effect of Windmill Farms on Military Readiness, Report to the congressional defense committees, Office of the Director of Defense Research and Engineering, 2006.

Devasthale, A. and Thomas, M. A.: An investigation of statistical link between inversion strength and carbon monoxide over Scandinavia in winter using AIRS data, Atmos. Environ., 56, 109114, doi:10.1016/j.atmosenv.2012.03.042, 2012.

Doviak, R. J. and Zrnić, D. S.: Doppler Radar and Weather Observations, Dover Publications, Mineola, New York, 2nd Edn., 2006.

Gallardo, B., Pérez, F., and Aguado, F.: Characterization Approach of Wind Turbine Clutter in the Spanish Weather Radar Network, in: Proceedings of the Fifth European Conference on Radar in Meteorology and Hydrology, Helsinki, Finland, ERAD, 2008.

Global Wind Energy Council: Global Wind Report, Annual market update 2013, Global Wind Energy Council, 2014.

Haase, G., Johnson, D., and Eriksson, K.-Å.: Analyzing the impact of wind turbines on operational weather radar products, in: Proceedings of the Sixth European Conference on Radar in Meteorology and Hydrology, Sibiu, Romania, 276-281, ERAD, 2010.

Isom, B. M., Palmer, R. D., Secrest, G. S., Rhoton, R. D., L., D. S. T., Allmon, Reed, J., Crum, T., and Vogt, R.: Detailed Observations of Wind Turbine Clutter with Scanning Weather Radars, J. Atmos. Oceanic Technol., 26, 894-910, doi:10.1175/2008JTECHA1136.1, 2009.

Kong, F.: Wind Turbine Clutter in Weather Radar: Characterization and Mitigation, Ph.D. thesis, University of Oklahoma, Norman, OK, United States, 2014.

Lemmon, J. J., Caroll, J. E., Sanders, F. H., and Turner, D.: Assessment of the Effects of Wind Turbines on Air Traffic Control Radars, Tech. Rep. TR-08-454, US Department of Commerse, National Telecommunications \& Information Administration, 2008.

Lute, C. and Wieserman, W.: ASR-11 radar performance assessment over a wind turbine farm, in: Proceedings of the 2011 IEEE Radar Conference, Kansas City, MO, United States, 226-230, IEEE, 2011.

Norin, L. and Haase, G.: Doppler Weather Radars and Wind Turbines, in: Doppler Radar Observations - Weather Radar, Wind Profiler, Ionospheric Radar, and Other Advanced Applications, edited by: Bech, J. and Chau, J. L., InTech, Croatia, doi:10.5772/39029, 2012. 
Patterson, W. L.: The Propagation Factor, $\mathrm{F}_{\mathrm{p}}$, in the Radar Equation, in: Radar Handbook, edited by Skolnik, M., McGraw-Hill, United States, 3rd Edn., 2008.

Poupart, G. J.: Wind farms impact on radar aviation interests, Tech. Rep. FES W/14/00614/00/REP, DTI PUB URN 03/1294, QinetiQ, 2003.

Rossa, A., Liechti, K., Zappa, M., Bruen, M., Germann, U., Haase, G., Keil, C., and Krahe, P.: The COST 731 Action: A review on uncertainty propagation in advanced hydrometeorological forecast systems, Atmos. Res., 100, 150-167, doi:10.1016/j.atmosres.2010.11.016, 2011.
Toth, M., Jones, E., Pittman, D., and Solomon, D.: DOW Radar Observations of Wind Farms, B. Am. Meteorol. Soc., 92, 987995, doi:10.1175/2011BAMS3068.1, 2011.

Vogt, R. J., Crum, T. D., Greenwood, W., Ciardi, E. J., and Guenther, R. G.: New Criteria for Evaluating Wind Turbine Impacts on NEXRAD Radars, in: Proceedings of WINDPOWER 2011, Anaheim, CA, United States, American Wind Energy Association, 2011.

Zeng, Y., Blahak, U., Neuper, M., and Jerger, D.: Radar Beam Tracing Methods Based on Atmospheric Refractive Index, J. Atmos. Oceanic Technol., 31, 2650-2670, doi:10.1175/JTECH-D13-00152.1, 2014 